ARTICLE

https://doi.org/10.1038/s41467-019-10903-9

\title{
IFN- $\beta$ is a macrophage-derived effector cytokine facilitating the resolution of bacterial inflammation
}

\author{
Senthil Kumaran Satyanarayanan (10 1,5, Driss El Kebir ${ }^{2,5}$, Soaad Soboh ${ }^{1,5}$, Sergei Butenko (1) ${ }^{1}$, Meriem Sekheri², \\ Janan Saadi ${ }^{1}$, Neta Peled (10) ${ }^{1}$, Simaan Assi ${ }^{1}$, Amira Othman², Sagie Schif-Zuck (1) ${ }^{1}$, Yonatan Feuermann³, \\ Dalit Barkan', Noa Sher ${ }^{4}$, János G. Filep (i) ${ }^{2} \&$ Amiram Ariel $^{1}$
}

The uptake of apoptotic polymorphonuclear cells (PMN) by macrophages is critical for timely resolution of inflammation. High-burden uptake of apoptotic cells is associated with loss of phagocytosis in resolution phase macrophages. Here, using a transcriptomic analysis of macrophage subsets, we show that non-phagocytic resolution phase macrophages express a distinct IFN- $\beta$-related gene signature in mice. We also report elevated levels of IFN- $\beta$ in peritoneal and broncho-alveolar exudates in mice during the resolution of peritonitis and pneumonia, respectively. Elimination of endogenous IFN- $\beta$ impairs, whereas treatment with exogenous IFN- $\beta$ enhances, bacterial clearance, PMN apoptosis, efferocytosis and macrophage reprogramming. STAT3 signalling in response to IFN- $\beta$ promotes apoptosis of human PMNs. Finally, uptake of apoptotic cells promotes loss of phagocytic capacity in macrophages alongside decreased surface expression of efferocytic receptors in vivo. Collectively, these results identify IFN- $\beta$ produced by resolution phase macrophages as an effector cytokine in resolving bacterial inflammation.

\footnotetext{
${ }^{1}$ Department of Biology and Human Biology, University of Haifa, Haifa 3498838, Israel. ${ }^{2}$ Department of Pathology and Cell Biology, University of Montreal, and Research Center, Maisonneuve-Rosemont Hospital, Montreal, QC H1T 2M4, Canada. ${ }^{3}$ ResCure Pharma, Haifa 3498838 , Israel. ${ }^{4}$ Tauber Bioinformatics Center, University of Haifa, Haifa 3498838, Israel. ${ }^{5}$ These authors contributed equally: Senthil Kumaran Satyanarayanan, Driss El Kebir, Soaad Soboh. Correspondence and requests for materials should be addressed to J.G.F. (email: janos.g.filep@umontreal.ca) or to A.A. (email: amiram@research.haifa.ac.il)
} 
T imely resolution of acute inflammation involves apoptotic death of tissue infiltrating neutrophils and their removal by neighboring macrophages to restore organ structure and function $^{1-3}$. Macrophages recognize apoptotic cells through unique 'eat me' signals and cognate receptors and engulf them in an efficient and tightly regulated-manner to avoid autoantigen exposure and metabolic stress ${ }^{4,5}$. In turn, the efferocytic macrophages undergo reprogramming that diverts proinflammatory cells to cells that drive tissue repair and resolution ${ }^{6-8}$. A unique subset of non-phagocytic pro-resolving macrophages is generated during resolving inflammation following high-burden efferocytosis and exposure to pro-resolving mediators ${ }^{9-11}$. These CD11b ${ }^{\text {low }}$ macrophages exhibit increased expression of $12 / 15-$ lipoxygenase (LO), an enzyme involved in the synthesis of specialized pro-resolving lipid mediators $(\mathrm{SPMs})^{12}$, reduced arginase 1 expression and emigration to distant sites 9 .

Neutrophil apoptosis is perceived as one of the control points that limits the number of neutrophils at sites of inflammation and pushes ongoing inflammation towards resolution. Inflammatory cytokines, growth factors and bacterial constituents, such as GMCSF, LPS and bacterial DNA (CpG DNA) can prolong the lifespan of neutrophils by delaying apoptosis ${ }^{13-15}$ predominantly by preserving the expression of the BCL2 family protein Mcl-1. By contrast, pro-resolving mediators, such as 15 -epi-LXA $\mathrm{A} 1$, resolvin $\mathrm{E} 1$, and cyclin-dependent kinase inhibitors ${ }^{1,16-19}$ facilitate degradation of Mcl-1 and consequently promote neutrophil apoptosis.

The role of type I interferons in host response to viruses is well established, whereas the contribution of these cytokines to antibacterial defense is less clear. IFN- $\beta$ has been reported to limit immune responses in some experimental models of inflammation through induction of IL-10 and/or inhibition of the inflammasome and IL-1 $\beta$ production ${ }^{20-24}$. IFN- $\beta$ was also found to block cancer progression by limiting the recruitment of pro-angiogenic neutrophils into tumors and deletion of endogenous IFN- $\beta$ was associated with delayed apoptosis of tumor-associated neutrophils ${ }^{25,26}$. By contrast, IFN- $\beta$ accelerates monocytic inflammation by attracting Ly- $6 \mathrm{C}^{+}$monocytes to sites of chronic inflammation ${ }^{27}$. Enhanced IFN- $\beta$ expression was detected in DNAse II-deficient embryonic macrophages that lack phagolysosomal degradation of DNA and hence accumulate large amounts of DNA from apoptotic cells ${ }^{28}$, thereby limiting erythrocyte differentiation and leading to severe anemia ${ }^{28}$. Thus, IFN- $\beta$ may exert important bioactivities consistent with a role in resolving inflammation.

Here we use an unbiased transcriptomic analysis to identify IFN- $\beta$ as an effector cytokine that is produced and acting during resolution of peritonitis and E.coli-evoked pneumonia. Mechanistically, IFN- $\beta$ overrides pro-survival cues and promotes apoptosis in murine and human neutrophils through STAT3 activation, and enhances efferocytosis by resolution phase macrophages, leading to the reprogramming of these macrophages to an anti-inflammatory and pro-resolving phenotype. Finally, we show that non-phagocytic macrophages are generated exclusively following the uptake of apoptotic cells in an irreversible manner, and this conversion is associated with reduced surface expression of efferocytic receptors. These findings identify IFN- $\beta$ as a macrophage-derived multi-pronged effector in resolving inflammation.

\section{Results}

Non-phagocytic macrophages have a distinct transcriptome. Since non-phagocytic macrophages compose a significant portion of resolution phase macrophages, we aimed to identify the molecular characteristics that distinguish these cells from their phagocytic counterparts. To this end, we performed transcriptome analysis of $\mathrm{PKH} 2^{\text {hi }}$ (phagocytic) and $\mathrm{PKH} 2^{\mathrm{lo} /-}$ (nonphagocytic) $\mathrm{F} 4 / 80^{+}$macrophages sorted from resolving exudates (Fig. 1a).

Comparative analysis of these two macrophage populations revealed disparate regulation of 3045 genes ( $\geq 2$-fold change among 13368 genes expressed in either subset). Of these genes, 1511 were upregulated and 1534 were downregulated in nonphagocytic macrophages. We performed gene ontology annotation to characterize the functional groups of the genes affected (Fig. 1b). As expected, non-phagocytic macrophages downregulated phagocytosis-associated functions, such as endocytosis, membrane invagination, small GTPase signaling and cell adhesion. Notably, non-phagocytic macrophages displayed significant metabolic changes, including increases in oxidative phosphorylation and oxidation-reduction processes. Nonphagocytic macrophages also showed reductions in gene groups associated with tissue repair, such as blood vessel development and morphogenesis, extracellular matrix, protein kinase activity and cell adhesion (required for wound retraction), while increasing locomotor activity. These findings are consistent with the origin of non-phagocytic CD11b low macrophages that differentiate from M2-like macrophages during the resolution of inflammation ${ }^{9}$ and with their capacity to migrate to distant sites. These macrophage subsets expressed low levels of markers for peritoneal resident macrophages, such as GATA6 (1.37 and 0.19 RPKM for phagocytic and non-phagocytic macrophages, respectively), Tim4 (relative values of 3.47 and 1.26 RPKM, respectively), and TGF- $\beta 2$ (relative values of 0.25 and 0.01 RPKM, respectively) with no detectable levels of another marker, GPR37 ${ }^{29,30}$. Moreover, F4/80 ${ }^{+} \mathrm{Tim} 4^{+}$macrophages were essentially absent at $66 \mathrm{~h}$ PPI in WT mice, while they were the major resident macrophage population in unchallenged mice (Supplementary Fig. 1), as previously reported ${ }^{31}$. Both subsets did express high levels of the monocyte markers CD115 (424.49 and 217.42 RPKM, respectively), and CD74 (1733.47 and 2631.85 RPKM, respectively), indicating that they originated exclusively from monocyte-derived macrophages rather than yolk sack-originated resident macrophages.

Non-phagocytic macrophages express IFN- $\beta$-associated genes. Our transcriptome analysis also revealed that non-phagocytic macrophages express a distinct protein signature profile (Table 1) consistent with upregulated IFN- $\beta$ expression and activity ${ }^{32}$. This profile is similar to that observed following macrophage activation due to impaired DNA degradation. These genes included Ifnb1, Ifitm1, Il1b, Isg15, Cxcl9, Ifit1, Ifit3, Ccl2, Isg20, Ifitm6, Ccl3, Ccl5 and Cxcl10. To confirm IFN- $\beta$-associated activation of nonphagocytic macrophages, we compared the expression of IFN- $\beta$ and its target gene Isg15 in non-phagocytic and phagocytic macrophages. Western blotting of peritoneal macrophages and cell-free exudates from $I f n b^{-/-}$mice revealed the existence of two different species of IFN- $\beta$ (Supplementary Fig. 2a, b), a 50-66 $\mathrm{kDa}$ isoform that is the most prevalent in resident and resolution phase macrophages, and a $25-35 \mathrm{kDa}$ isoform that prevails in the exudates, which was scarcely detectable in macrophages. Notably, all the secreted isoforms were diminished at $16 \mathrm{~h}$ PPI upon clodronate-mediated depletion of resident peritoneal macrophages (Supplementary Fig. 2c). However, peritoneal IFN- $\beta$ levels were not abrogated by administering clodronate-containing liposomes during the resolution phase (Supplementary Fig. $2 c-d)$, probably due to IFN- $\beta$ secretion by non-phagocytic macrophages that cannot be depleted by clodronate. Furthermore, during the resolution phase, we detected intracellular IFN$\beta$ protein only in $\mathrm{F} 4 / 80^{+}$macrophages and not in lymphocytes or 
a
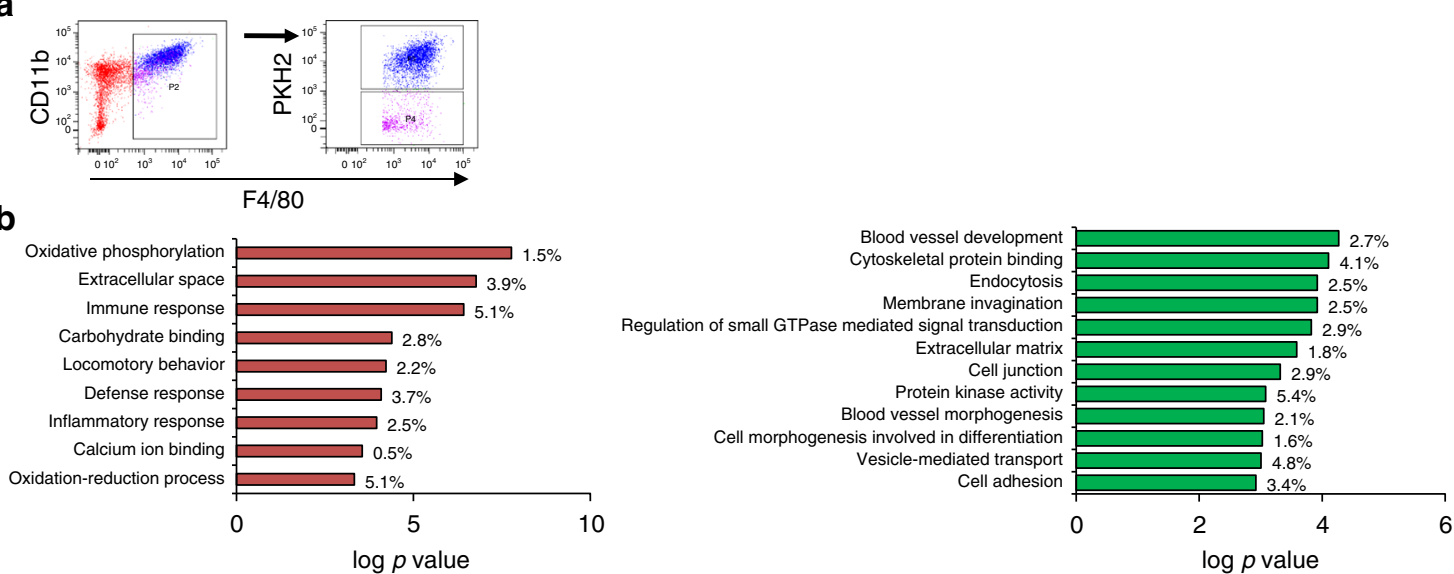

C
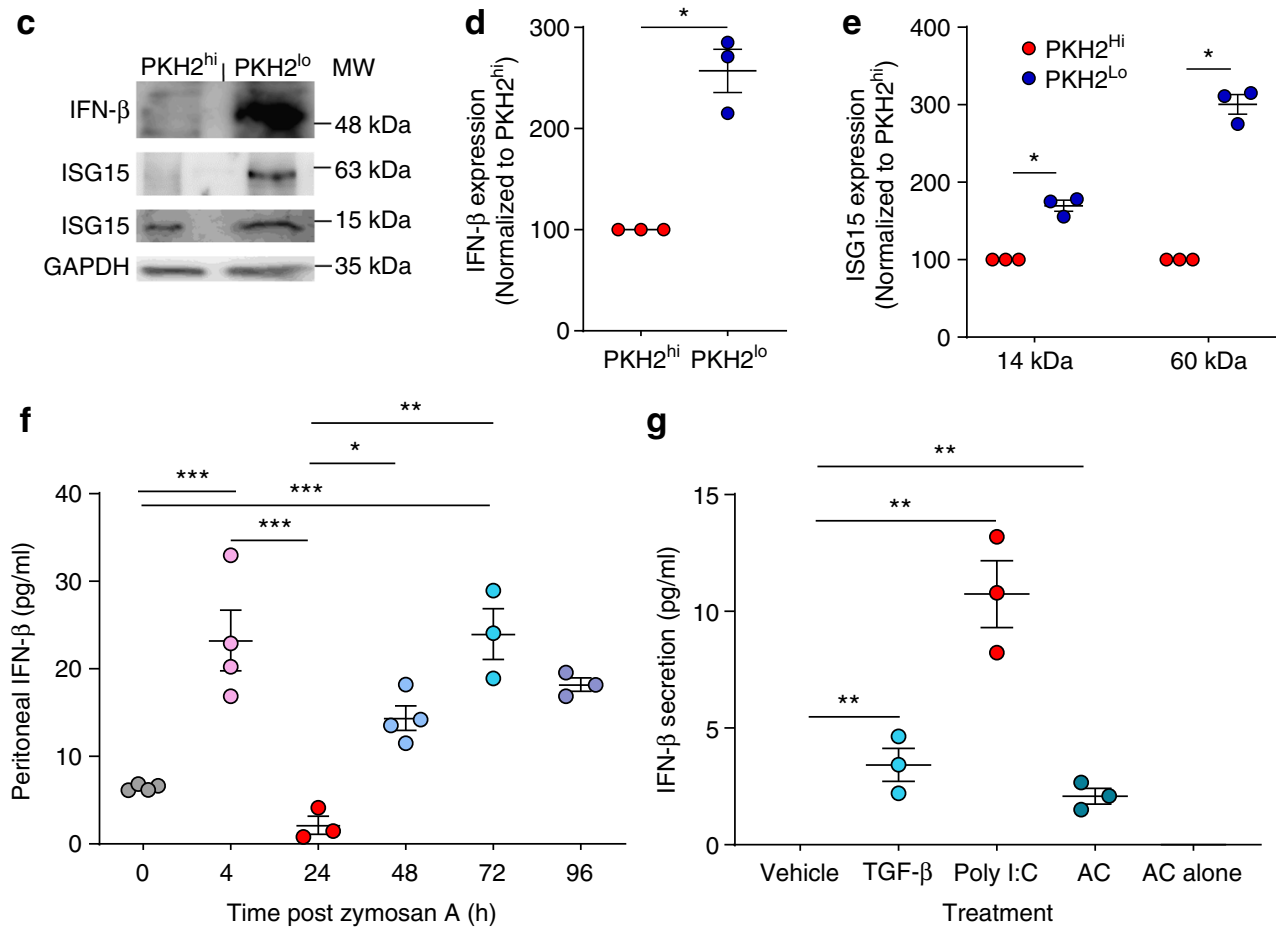

Fig. 1 Non-phagocytic resolution phase macrophages express IFN- $\beta$. a, b Male mice were injected intraperitoneally with zymosan A (1 mg/mouse) followed by an injection of PKH2-PCL at $62 \mathrm{~h}$. After $4 \mathrm{~h}$, the peritoneal cells were recovered and immuno-stained for F4/80 and CD11b. Then, F4/80+ macrophages were sorted based on the extent of PKH2-PCL acquisition (PKH2 +/- populations; $>98 \%$ purity) using the FACSAria III sorter (illustrated in (a). The collected cells were immediately used for RNA extraction (with RNA integrity value above 7.5), and a gene expression microarray analysis was performed using Illumina hiSeq 2500. Differential gene expression analysis and gene ontology (GO) enrichment were performed for genes that were significantly upregulated (b, left panel) or downregulated (b, right panel) in non-phagocytic/satiated ( $\mathrm{PKH} 2-\mathrm{PCL} \mathrm{L}^{\mathrm{lo}}$ ) macrophages in comparison to phagocytic (PKH2$P C L$ hi) ones. The results indicate the statistical significance of the GO term and the percentage of enrichment is presented. $\mathbf{c}-\mathbf{e}$ Expression of IFN- $\beta$ and ISG15 in sorted satiated and phagocytic macrophages. Representative results (c) and mean \pm SEM (d, e) for three independent experiments. ${ }^{\star} P<0.05$ (Student's $t$ test). $\mathbf{g}$, h Peritoneal exudates were collected from unchallenged mice $(0 \mathrm{~h})$ or following peritonitis for $4-96 \mathrm{~h}$. IFN- $\beta$ content in cell-free fluids was determined by ELISA (f). Results are mean \pm SEM from three $(24,72,96 \mathrm{~h})$ or four $(0,4,48 \mathrm{~h})$ mice. ${ }^{\star} P<0.05,{ }^{\star \star} P<0.01,{ }^{\star \star \star} P<0.005(T u k e y$ 's $\mathrm{HSD}$ ). Alternatively, resolution phase macrophages were recovered $66 \mathrm{~h}$ post peritonitis initiation (PPI) and incubated with TGF- $\beta$ ( $5 \mathrm{ng} / \mathrm{ml})$, poly (I:C) $(4 \mu \mathrm{g} / \mathrm{ml})$ or apoptotic cells (AC, at a ratio of 1:5) for $24 \mathrm{~h}$. Culture supernatants were then collected and IFN- $\beta$ content was measured (g). Culture media from apoptotic cells served as control. Results are representative from three independent experiments. ${ }^{\star} P<0.05,{ }^{\star \star} P<0.01,{ }^{\star \star \star} P<0.005$ (Tukey's HSD). Source data are provided as a Source Data file

eosinophils (Supplementary Fig. 2e). Ifn $b^{-1-}$ macrophages had the same background staining as the $2^{\text {nd }}$ antibody control. Moreover, the $25-35 \mathrm{kDa}$ isoforms and, to a higher extent, the 50 $\mathrm{kDa}$ isoform were present in both resident and resolution phase macrophages, whereas the $66 \mathrm{kDa}$ isoform was exclusively expressed in resolution phase macrophages (Supplementary Fig. 2f). Analysis of organelle fractions of RAW264.7 macrophages that were incubated with apoptotic cells revealed presence of the 50 and $66 \mathrm{kDa}$ isoforms of IFN- $\beta$ in the ER and secretory vesicles (which contain calnexin and rab7, respectively) (Supplementary Fig. $2 \mathrm{~g}$ ). The $25-35 \mathrm{kDa}$ isoforms are present in the ER and negligible in secretory vesicles. These results suggest that the $25 \mathrm{kDa}$ IFN- $\beta$ would undergo posttranslational modifications in the ER that would prevent its secretion. Once these 


\begin{tabular}{|c|c|c|c|c|c|c|}
\hline Gene & $\mathrm{PKH}^{\mathrm{hi}}$ & & PKH2' & & Fold change $(\log 2)$ & $Q$ value \\
\hline Ifnb1 & -0.34 & 0.33 & 3.26 & 4.38 & 3.89 & 0.0011 \\
\hline Ifitm1 & 6.21 & 7.00 & 8.67 & 9.47 & 2.47 & 0.0024 \\
\hline $117 b$ & 11.20 & 10.99 & 13.67 & 13.34 & 2.41 & 0.0006 \\
\hline $\operatorname{lsg} 15$ & 7.12 & 6.07 & 9.09 & 8.23 & 2.03 & 0.0006 \\
\hline $\mathrm{CxCl9}$ & 2.19 & 1.35 & 3.99 & 3.60 & 1.97 & 0.0006 \\
\hline Ifit1 & 5.06 & 3.15 & 6.82 & 5.12 & 1.80 & 0.0006 \\
\hline Ifit3 & 1.45 & 0.34 & 3.31 & 1.98 & 1.79 & 0.0006 \\
\hline $\mathrm{Ccl} 2$ & 8.55 & 8.75 & 10.04 & 10.50 & 1.64 & 0.0159 \\
\hline $\operatorname{lsg} 20$ & 3.12 & 3.13 & 4.48 & 4.99 & 1.63 & 0.0006 \\
\hline Ifitm6 & 7.69 & 7.81 & 8.88 & 9.70 & 1.60 & 0.0062 \\
\hline $\mathrm{Ccl} 3$ & 8.85 & 8.77 & 9.86 & 10.30 & 1.28 & 0.0006 \\
\hline $\mathrm{Ccl} 5$ & 8.37 & 7.16 & 9.55 & 8.13 & 1.12 & 0.0006 \\
\hline Cxcl10 & 7.60 & 7.58 & 8.08 & 8.89 & 0.95 & 0.0006 \\
\hline
\end{tabular}

modifications are removed, IFN- $\beta$ is immediately secreted, hence the $25-35 \mathrm{kDa}$ isoforms are the only forms detected consistently in peritoneal fluids, but scarcely inside macrophages. Notably, non-phagocytic macrophages $\left(\mathrm{PKH}_{2}{ }^{\mathrm{lo}}\right)$ expressed significantly higher levels of the $50 \mathrm{kDa}$ isoform and ISG15 (2.56 and 1.7 fold increase, respectively) than their phagocytic counterparts $\left(\mathrm{PKH} 2^{\mathrm{hi}}\right.$ ) (Fig. 1c-e). In addition to the predicted band at $15 \mathrm{kDa}$, we also detected ISG15 immunoreactivity at the $60 \mathrm{kDa}$ band with 3-fold higher level in non-phagocytic than phagocytic macrophages. This band likely corresponds to a protein modified by the ubiquitin-like nature of ISG15. Thus, non-phagocytic resolution phase macrophages exhibit increased expression of IFN- $\beta$ and its downstream signaling.

Since non-phagocytic macrophages are generated during the resolution phase of inflammation, we monitored the kinetics of peritoneal fluid IFN- $\beta$ during insult. We detected two peaks in IFN- $\beta$ level during zymosan A-induced peritonitis in mice. The first peak occurred during the inflammatory phase (at $4 \mathrm{~h}$ post peritonitis initiation (PPI)), and the second one during the resolution phase (at around $72 \mathrm{~h}$ PPI) (Fig. 1f). Unchallenged peritoneal macrophages expressed IFN- $\beta$ protein, which expression was reduced at $4 \mathrm{~h}$ upon exposure to zymosan A. Subsequently, at $24-72 \mathrm{~h}$ PPI, IFN- $\beta$ levels in peritoneal macrophages exceeded the expression displayed in unchallenged macrophages (Supplementary Fig. 2f). These results would indicate production of IFN- $\beta$ by peritoneal resident macrophages prior to challenge and its release in response to inflammatory stimuli. Monocytes would then infiltrate the inflamed peritoneum, differentiate to macrophages and phagocytose apoptotic PMN, eventually resulting in loss of phagocytosis and IFN- $\beta$ expression during the resolving phase. To test this hypothesis, we challenged resolution phase macrophages with apoptotic cells, the pro-resolving cytokine TGF- $\beta$ or the viral mimicry poly (I:C). Apoptotic cells or TGF- $\beta$ evoked modest increases in IFN- $\beta$ secretion, whereas poly(I:C) resulted in a robust increase (Fig. 1g). These findings suggest that progressive accumulation of apoptotic PMN by high-burden non-phagocytic macrophages during resolving inflammation leads to de novo synthesis and secretion of IFN $-\beta$ and the activation of IFN- $\beta$ signaling.

IFN- $\beta$ contributes to timely resolution of $E$.coli pneumonia. To explore the role for IFN- $\beta$ in resolving inflammation, we studied the kinetics of its production and development of PMN apoptosis in a model of spontaneously resolving bacterial pneumonia. As anticipated, intratracheal instillation of live E. coli evoked neutrophil-mediated lung injury that peaked at around $6 \mathrm{~h}$ and resolved within $48 \mathrm{~h}$ without treatment (Fig. 2). WT mice rapidly cleared bacteria (Fig. 2a), followed by rapid decline in E. coliinduced edema (Fig. 2b, c), tissue and BAL fluid neutrophils (Fig. 2e-g) and increases in BAL fluid monocytes (Fig. 2h). These changes were associated with significant elevations in BAL fluid IFN- $\beta$ level, peaking at $24 \mathrm{~h}$ post-E. coli instillation (Fig. $2 \mathrm{~d}$ ) parallel with increases in the percentage of apoptotic neutrophils assessed by Annexin- $\mathrm{V}$ staining (Fig. 2i) and the percentage of macrophages containing apoptotic bodies (Fig. 2j). We also detected a strong positive correlation between BAL fluid IFN- $\beta$ levels and percentage of apoptotic neutrophils (Fig. 2k).

Next, we investigated the impact of neutralizing IFN- $\beta$ activity on the resolution of $E$. coli pneumonia. We found that pretreatment of mice with an anti-IFN- $\beta$ antibody delayed $E$. coli clearance at $24 \mathrm{~h}$ (Fig. 3a) while enhanced E. coli-evoked edema formation (Fig. 3b, c), lung myeloperoxidase content, an index of neutrophil accumulation (Fig. 3d), BAL fluid total leukocyte (Fig. 3e), and PMN (Fig. 3f) and monocyte counts (Fig. $3 \mathrm{~g}$ ) in comparison to IgG controls. By contrast, the antiIFN- $\beta$ antibody markedly reduced the percentage of apoptotic PMN in the BAL fluid at $24 \mathrm{~h}$ as compared to IgG (Fig. 3h). We detected slight increases in the percentage of apoptotic PMN at $48 \mathrm{~h}$ post E. coli, likely due to hampered efferocytosis by macrophages. Along these lines, the anti-IFN- $\beta$ antibody impinged efferocytosis at both $24 \mathrm{~h}$ and $48 \mathrm{~h}$ (Fig. 3i). Thus, blocking IFN- $\beta$ abrogates the resolution of inflammation by limiting PMN apoptosis and efferocytosis and preventing clearance of infiltrating PMN.

IFN- $\beta$ promotes apoptosis in inflammatory neutrophils. To investigate the mechanisms by which IFN- $\beta$ governs resolution, we next studied the impact of IFN- $\beta$ on apoptosis of inflammatory neutrophils. We detected similar percentages of apoptotic PMN in the peritoneum of Ifn $b^{+/+}$and Ifnb $b^{-/-}$mice at $4 \mathrm{~h}$ PPI (Fig. 4a), whereas neutrophils from Ifn $b^{-/-}$mice displayed lower apoptosis rate than their Ifn $b^{+/+}$counterparts following $24 \mathrm{~h}$ culture ex vivo and reduced inhibition of apoptosis by the caspase inhibitor Q-VD. Conversely, treatment of peritoneal PMN ex vivo with murine IFN- $\beta$ led to increases in the number of annexin-Vpositive cells (Fig. 4b) and cleavage of caspase 3 (Fig. 4c), indicating increased apoptosis. Furthermore, reduced peritoneal leukocyte and neutrophil numbers at $4 \mathrm{~h}$ PPI were observed in Ifn $b^{-/-}$or anti-IFN- $\beta$-treated WT mice, as compared with untreated $\mathrm{Ifnb}^{+/+}$ones (Supplementary Fig. 3). These results indicate that IFN- $\beta$ promoted resolution by enhancing the apoptosis of inflammatory neutrophils rather than by inhibiting neutrophil influx into the inflamed tissue.

To confirm that our findings in mice translate to human innate immunity, we cultured human neutrophils for $24 \mathrm{~h}$ with bacterial DNA (CPG DNA) in the presence of IFN- $\beta$. Confirming previous results $^{14}$, CpG DNA prolonged neutrophil survival by delaying constitutive apoptosis as indicated by reduced staining for annexin- $\mathrm{V}$, prevention of the collapse of mitochondrial transmembrane potential and hypoploid nuclei (Fig. $4 \mathrm{~d}-\mathrm{g}$ ). While IFN- $\beta$ alone failed to affect neutrophil apoptosis (Supplementary Fig. 4a), pretreatment of PMN with IFN- $\beta$ countered the survival cue from $\mathrm{CpG}$ DNA in a concentration-dependent manner (Fig. 4d-g). Likewise, when PMN were first challenged with CpG DNA and then treated with IFN- $\beta$ at 60 min post-CpG DNA, the pro-apoptotic action of IFN- $\beta$ was dominant over CpG DNAgenerated effects (Fig. 4h-k). Notably, this inhibitory action was still detectable when IFN- $\beta$ was added $120-240$ min post-CpG DNA (Supplementary Fig. b, c). IFN- $\beta$ attenuated CpG DNA preservation of Mcl-1 expression (Fig. 4l, m), a key regulator of life span in human PMN ${ }^{33,34}$. Furthermore, the pro-apoptotic 
a

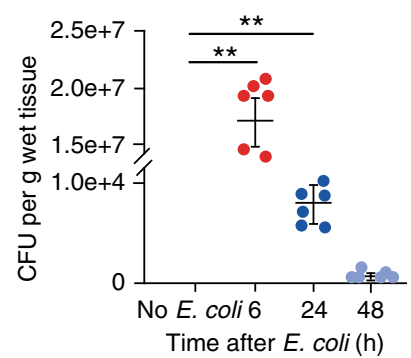

e

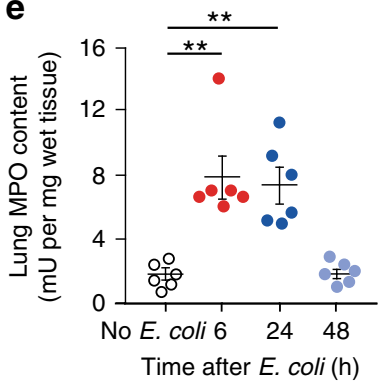

i

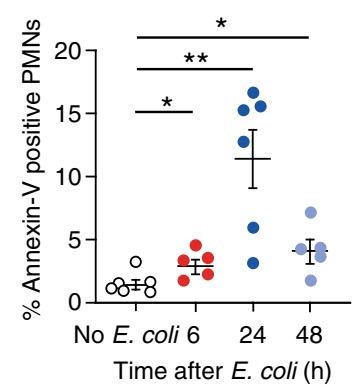

b
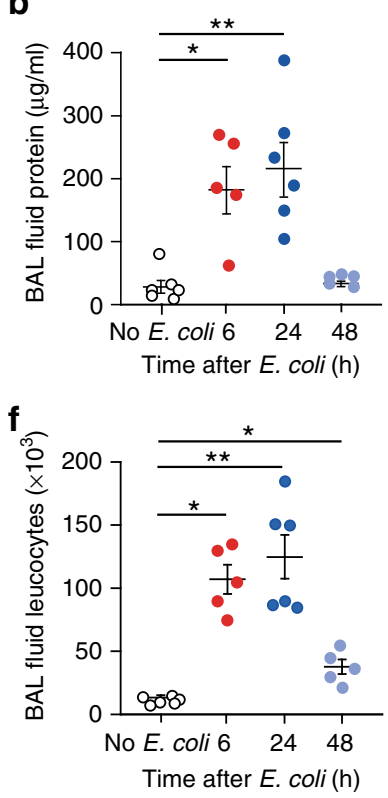

j

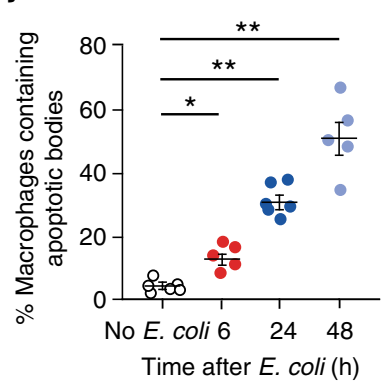

C

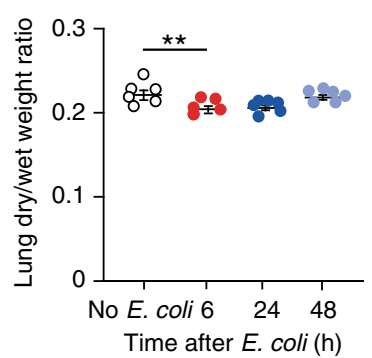

9 ต

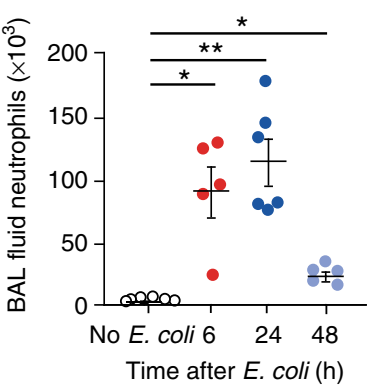

$\mathbf{k}$

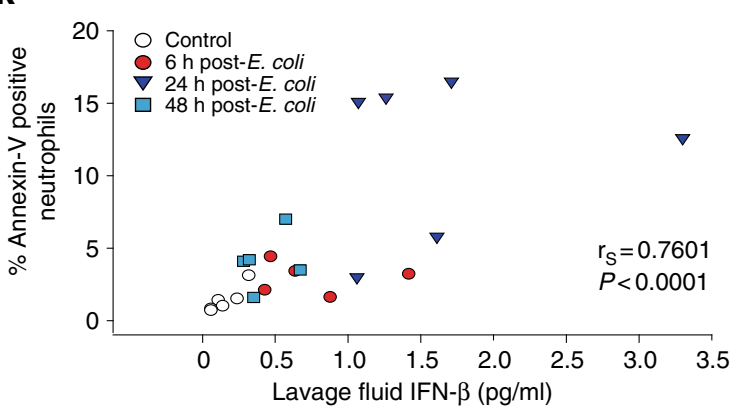

d

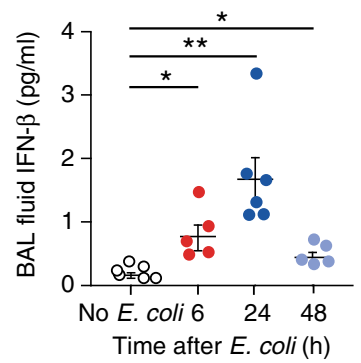

h

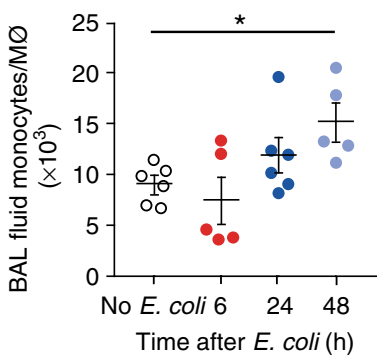

Fig. 2 Enhanced IFN- $\beta$ production during the resolution of E.coli pneumonia. Under isoflurane anesthesia, female C57BL/6 mice were injected

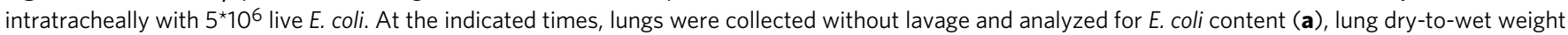
ratio (c) and tissue MPO activity (e). In separate groups of mice bronchoalveolar lavage fluid protein concentration (b), IFN- $\beta$ levels (d), total leukocyte (f), neutrophil (g) and monocyte/macrophage numbers (h) and the percentage of annexin- $\mathrm{V}$-positive (apoptotic) PMN (i) and the percentage of BAL fluid macrophages containing apoptotic bodies (j) were determined. Results are means \pm SEM ( $n=6$ mice per group). ${ }^{\star} P<0.05$, ${ }^{\star} P<0.01$ (Dunn's multiple contrast hypothesis test). k Neutrophil apoptosis positively correlates with lavage fluid IFN- $\beta$ levels (Spearman correlation analysis). Source data are provided as a Source Data file

action of IFN- $\beta$ was also dominant over survival cues generated by LPS or the acute-phase protein serum amyloid A (Supplementary Fig. $5 a-p)$. By contrast, IFN- $\beta$ failed to affect PMN apoptosis induced by the phagocytosis of E. coli (Supplementary Fig. $5 q, r$ ). Thus, IFN- $\beta$ can efficiently antagonize survival signals and facilitate apoptosis in activated human neutrophils, but not under homeostatic settings.

IFN- $\beta$ drives neutrophil apoptosis through STAT3. To investigate the signaling events underlying IFN- $\beta$ promotion of apoptosis in human PMN, we probed cytosolic and nuclear fractions of cell lysates with antibodies against phospho-STAT1 or phospho-STAT3. We detected significant increases in the levels of phosphorylated STAT1 and STAT3 both in the cytosolic or nuclear fractions of IFN- $\beta$-exposed PMN (Fig. $5 \mathrm{a}, \mathrm{b}$ ), whereas CpG DNA did not affect phosphorylation of STAT1 or STAT3. Next, we assessed the contribution of STAT signaling to the proapoptotic effect of IFN- $\beta$. Preincubation of PMN with the STAT3 inhibitor WP1066, but not the STAT1 inhibitor fludarabine, efficiently blocked the pro-apoptotic action of IFN- $\beta$ in PMN challenged with CpG DNA (Fig. 5c-f).
CpG DNA reduced surface expression of IFNaR1 that binds IFN- $\beta$ within $2 \mathrm{~h}$ of culture (Supplementary Fig. $6 \mathrm{a}-\mathrm{b}$ ), whereas IFN- $\beta$ did not affect the uptake of labeled oligodeoxynucleotides by PMN (Supplementary Fig. 6c). These findings indicate the ability of IFN- $\beta$ to redirect neutrophils to apoptosis even when its receptor is slightly downregulated in the presence of CpG DNA, and suggest that diminishing IFNaR1 expression is part of the survival cascade induced by CpG DNA. The IFN- $\beta$ pro-apoptotic signal appears to be predominantly mediated through STAT3 activation and not by reducing CpG DNA uptake by human PMN.

IFN- $\boldsymbol{\beta}$ enhances macrophage efferocytosis. Having documented enhanced IFN- $\beta$ generation by non-phagocytic macrophages and IFN- $\beta$ promotion of PMN apoptosis, next we tested whether it could promote efferocytosis. We found that macrophages from If $n b^{-/-}$mice contained lower amounts of apoptotic nuclei and engulfed on average significantly lower numbers of apoptotic PMN than macrophages from Ifn $b^{+/+}$mice (Fig. 6a, b). Notably, If $n b^{-/}$mice contained 1.85 -fold higher numbers of macrophages that did not engulf PMN at all than Ifn $b^{+/+}$mice (Fig. $6 \mathrm{c}$ ). 

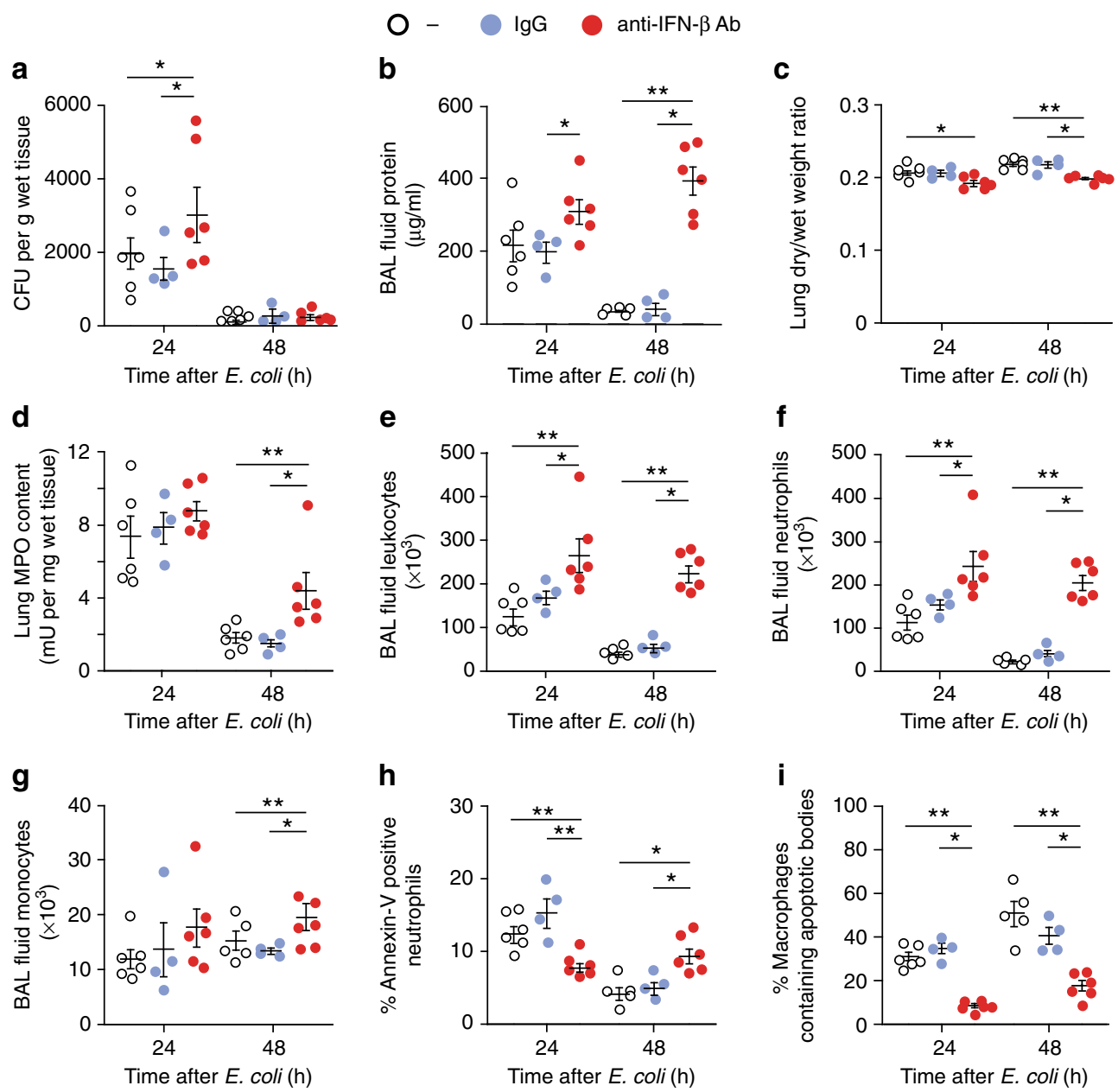

Fig. 3 IFN- $\beta$ is essential for the resolution of E. coli pneumonia. Female C57BL/6 mice were injected intratracheally with $5^{\star} 10^{6}$ live $E$. coli with anti-IFN- $\beta$ antibody (1 $\mathrm{gg} / 20 \mathrm{~g}$ b.w.) or isotype control ( $\mathrm{ggG}$ ) or saline (" $\left.{ }^{\prime \prime}\right)$. At 24 or $48 \mathrm{~h}$, lungs were removed without lavage and analyzed for E. coli content (a), lung dry-to-wet weight ratio (c) and tissue MPO activity (d). In separate groups of mice bronchoalveolar lavage fluid protein concentration (b), total leukocyte (e), neutrophil (f) and monocyte/macrophage numbers $(\mathbf{g})$, the percentage of annexin-V-positive (apoptotic) PMN (h), and the percentage of macrophages containing apoptotic bodies (i) were determined. Results are means \pm SEM ( $n=6$ mice per group for control and anti-IFN- $\beta$, or 4 for IgG). ${ }^{\star} P<0.05,{ }^{\star \star} P<0.01$ (Dunn's multiple contrast hypothesis test). Source data are provided as a Source Data file

Since monocyte/macrophage migration to and from the resolving site may confound detection of efferocytosis in vivo ${ }^{9}$, we evaluated the direct uptake of CypHer-loaded apoptotic cells by resolution phase If $n b^{-/-}$macrophages ex vivo (Fig. 6d, e shows representative results). We detected significant decreases in apoptotic cell uptake by If $n b^{-/-}$macrophages and in the percentage of efferocytosing macrophages (Fig. 6e-g). Importantly, the reduction in efferocytosis was associated with increased motile morphology as If $n b^{-/}$macrophages appeared to be more spread and activated, and had more extensive filopodia (Fig. 6e, arrowheads). Of note, the reduction in efferocytosis in If $\mathrm{nb}^{-/-}$ macrophages was not due to changes in macrophage origin or number. Indeed, the recovered peritoneal macrophage population was still dominated by Tim4 ${ }^{-}$macrophages (Supplementary Fig. 1a, b) and macrophage numbers were in fact reduced in If $n b^{-1-}$ mice at $48 \mathrm{~h}$ PPI (Fig. 6h), whereas the number of peritoneal resident macrophages was similar in unchallenged wild type and If $\mathrm{nb}^{-1-}$ mice (Supplementary Fig. 1a-c). These results would suggest an important role for IFN- $\beta$ in attracting monocytes to inflamed sites, as previously reported in pristane-evoked inflammation ${ }^{27}$. Taken together, these findings indicate that IFN$\beta$ enhances efferocytosis by resolution phase macrophages in vivo and ex vivo.
IFN- $\beta$ promotes reprogramming of resolution phase macrophages. The uptake of apoptotic cells by macrophages leads to reduced secretion of pro-inflammatory cytokines and increased secretion of anti-inflammatory and pro-resolving mediators when stimulated by microbial moieties ${ }^{35-37}$. This process is termed reprogramming and is critical for the prevention of autoimmunity and the restoration of tissue architecture and function ${ }^{4,7}$. Since If $n b^{-/-}$macrophages are less efferocytic and more activated than their If $n b^{+/+}$counterparts, we investigated whether reprogramming is hampered in these macrophages. We found that resolution phase If $n b^{-/-}$macrophages secrete significantly lower amounts of IL-10 (55\% decrease) and significantly higher amounts of IL-6, IL12 and CCL3 (10\%, 18\%, and 120\% increases, respectively) upon LPS stimulation than their If $n b^{+/+}$counterparts (Fig. $7 \mathrm{a}-\mathrm{d}$ ). Furthermore, Ifnb ${ }^{+/+}$macrophages significantly upregulated IL10 (183\% increase) and diminished IL-12 secretion (73\% reduction) in response to IFN- $\beta$, but not IFN- $\alpha$ ex vivo (Fig. $7 \mathrm{e}-\mathrm{f}$ ). Notably, peritoneal resident macrophages from $I f n b^{-1-}$ mice did not show reduced reprogramming. Rather, these macrophages secreted significantly reduced levels of either IL-12 and TNFa or IL-10 in comparison to their Ifn $b^{+/+}$counterparts (Supplementary Fig. 1d-f). Thus, IFN- $\beta$ directly promotes the reprogramming of monocyte-derived resolution phase macrophages. 
a

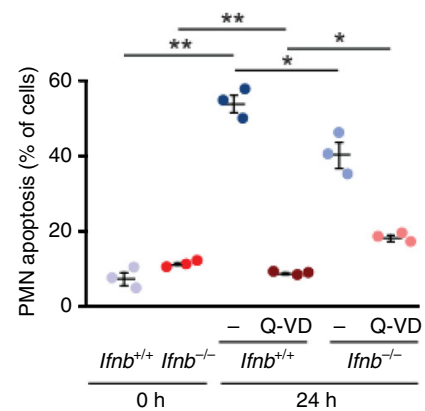

C

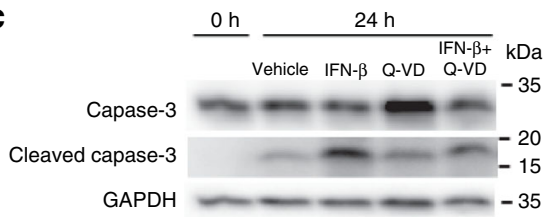

b

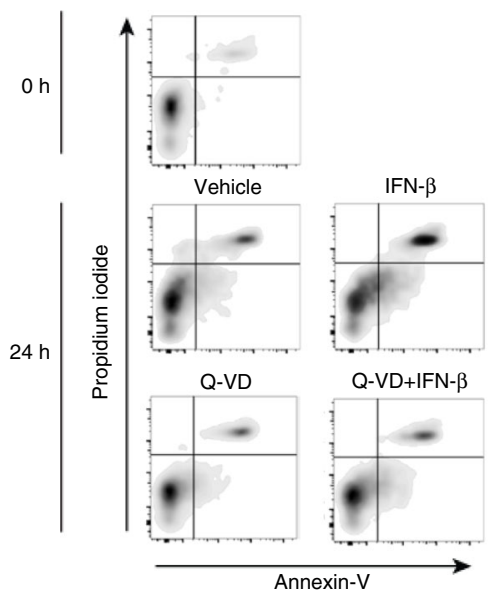

O Late apoptosis - Early apoptosis

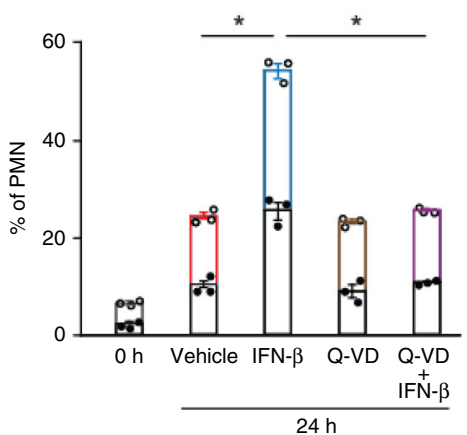

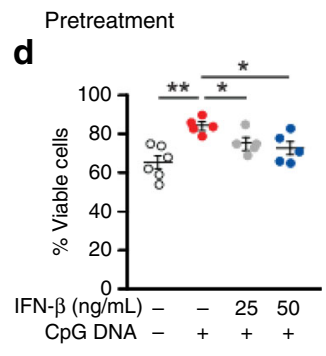

h

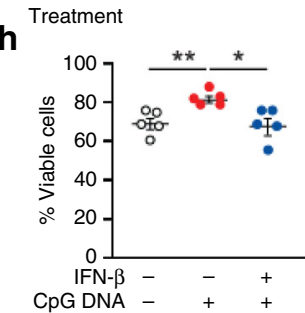

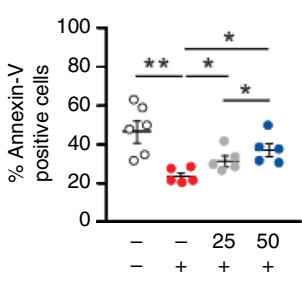

i

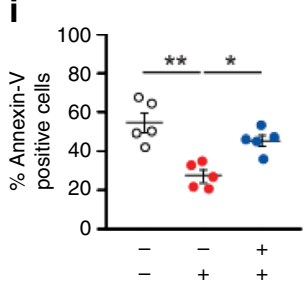

f
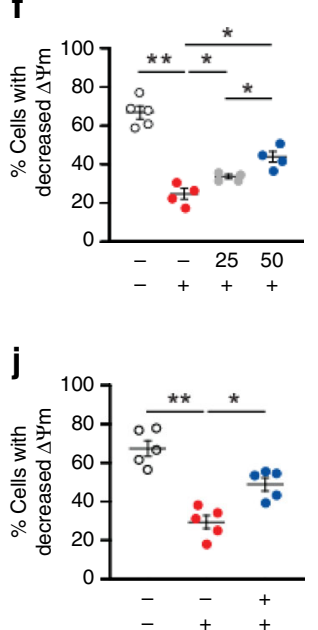

g

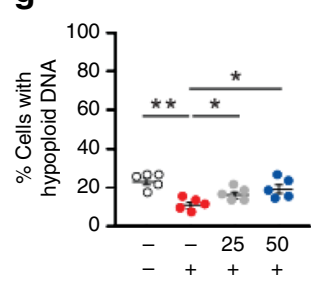

$\mathbf{k}$

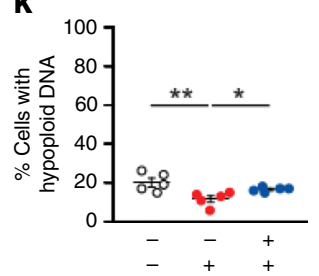

I
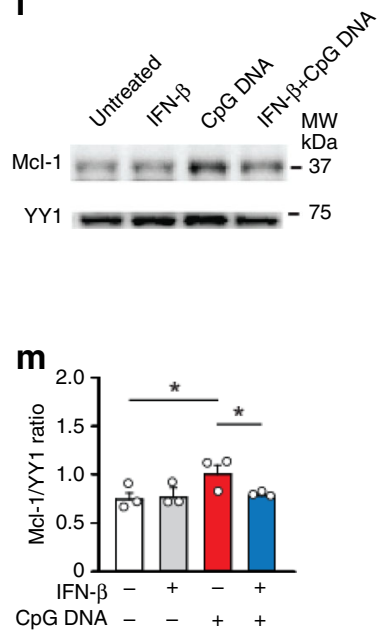

Fig. 4 IFN- $\beta$ promotes apoptosis in mouse and human neutrophils. a Peritoneal PMN were recovered from male Ifnb $/ /+$ or Ifnb $b^{-/-}$mice at $4 \mathrm{~h}$ PPI and stained immediately with annexin- $V$ and propidium iodide to assess apoptosis and cell viability, respectively with flow cytometry. Alternatively, cells were cultured with or without the pan-caspase inhibitor Q-VD $(10 \mu \mathrm{M})$ for $24 \mathrm{~h}$ and then assessed for apoptosis. Results are mean \pm SEM from three independent experiments. ${ }^{\star} P<0.05,{ }^{\star \star} P<0.01$ (Tukey's HSD). b, c Peritoneal PMN were recovered from Ifnb ${ }^{+/+}$mice $24 \mathrm{~h}$ PPI and cultured ex vivo with IFN- $\beta(20 \mathrm{ng} / \mathrm{ml})$ and/or Q-VD $(10 \mu \mathrm{M})$ for $24 \mathrm{~h}$. Apoptosis was evaluated as above. In some experiments, PMN lysates were prepared after $6 \mathrm{~h}$ culture and immunoblotted for cleaved (active) caspase-3. Results are representatives for three independent experiments. ${ }^{\star} P<0.05$ (Tukey's HSD). d-g Human PMN $\left(5 \times 10^{6}\right.$ cells $\left./ \mathrm{ml}\right)$ were pretreated with human recombinant IFN- $\beta(25-50 \mathrm{ng} / \mathrm{ml})$ for $10 \mathrm{~min}$ and then challenged with CpG DNA (1.6 $\left.\mu \mathrm{g} / \mathrm{ml}\right)$ or (h-k) first challenged with CpG DNA $(1.6 \mu \mathrm{g} / \mathrm{ml})$ and then treated with IFN- $\beta(50 \mathrm{ng} / \mathrm{ml})$ at $60 \mathrm{~min}$ post-CpG DNA. Cell viability (d, $\mathbf{h})$, annexin-V staining $(\mathbf{e}, \mathbf{i})$, mitochondrial transmembrane potential $(\Delta \Psi \mathrm{m} ; \mathrm{CMXRos}$ staining, $\mathbf{f}, \mathbf{j})$ and nuclear DNA content $(\mathbf{g}, \mathbf{k})$ were analyzed after culturing neutrophils for $24 \mathrm{~h}$ with CpG DNA. Results are mean \pm SEM of 5 experiments with different blood donors. ${ }^{\star} P<0.05,{ }^{\star \star} P<0.01$ (Dunn's multiple contrast hypothesis test). I, $\mathbf{m}$ Human PMN lysates, prepared following $4 \mathrm{~h}$ culture with IFN- $\beta(50 \mathrm{ng} / \mathrm{ml})$ with or without CpG DNA, were immunoblotted for Mcl-1 or the ubiquitous transcription factor $Y Y 1$ as a loading control. Representative blots (I) and densitometry analyses (m) for three independent experiments. ${ }^{\star} P<0.05$, ${ }^{\star \star} P<0.01$ (Dunn's multiple contrast hypothesis test). Source data are provided as a Source Data file

The uptake of apoptotic PMN and pro-resolving mediators promote macrophage loss of phagocytosis and consequently their conversion from the CD11bhigh to CD11blow phenotype hallmarked by reduced expression of the arginase 1 and increased expression of $12 / 15-\mathrm{LO}^{9,10}$. Our results indicate that IFN- $\beta$ also facilitates these processes either ex vivo by increasing the percentage of CD11b bow macrophages (Fig. $7 \mathrm{~g}$ ), or in vivo by reducing arginase 1 expression and upregulating $12 / 15-\mathrm{LO}$ expression (Fig. $7 \mathrm{~h}-\mathrm{i}$ ).

IFN- $\beta$ accelerates the resolution of bacterial inflammation. Pro-resolving lipid mediators, such as RvD1 and RvD5, have been shown to enhance E. coli clearance and to promote the resolution of bacterial inflammation in vivo ${ }^{38}$. Having shown that genetic deletion or neutralization of IFN- $\beta$ limited various resolutionpromoting indices, we examined whether treatment with exogenous IFN- $\beta$ could accelerate the resolution of inflammation. Treatment of mice with IFN- $\beta$ at the peak of inflammation resulted in accelerated clearance of E. coli at $24 \mathrm{~h}$ (Fig. 8a), marked reductions in edema (Fig. $8 \mathrm{~b}, \mathrm{c}$ ), lung myeloperoxidase content (Fig. 8d), BAL fluid total leukocytes (Fig. 8e), and PMN counts (Fig. 8f) as compared with vehicle control. Furthermore, IFN- $\beta$ also enhanced monocyte/macrophage numbers in the lungs at $24 \mathrm{~h}$ post-E. coli, increased the percentage of apoptotic 
a

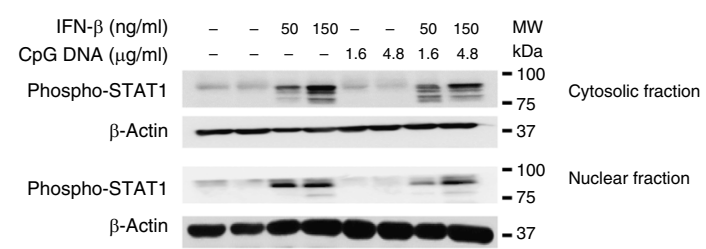

b

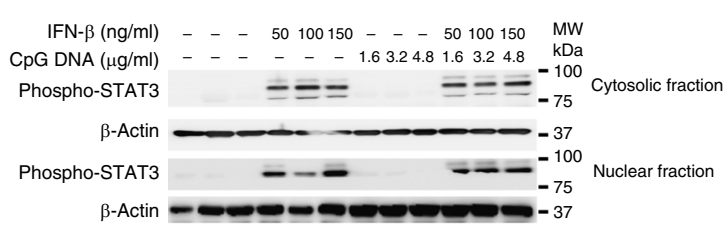

C

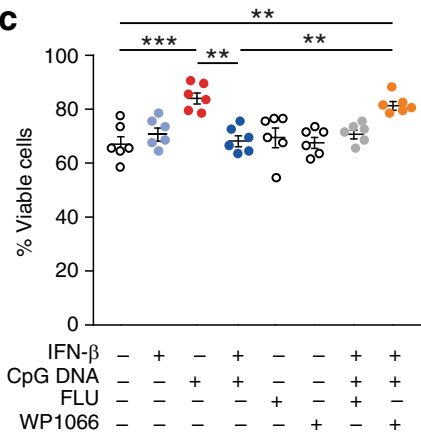

e

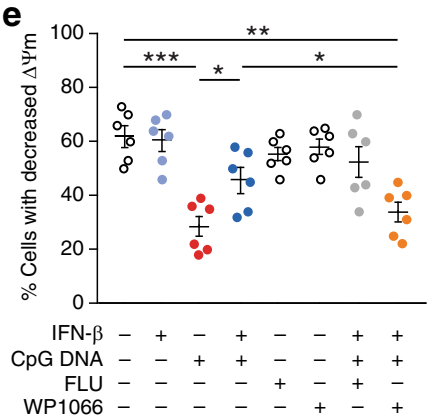

d

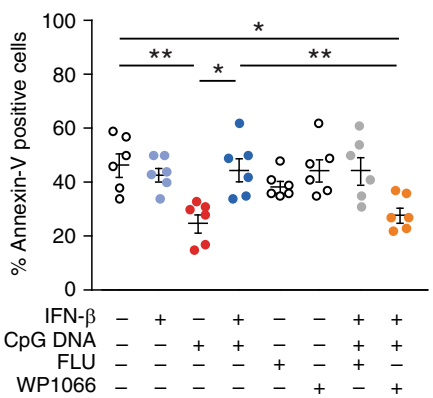

f

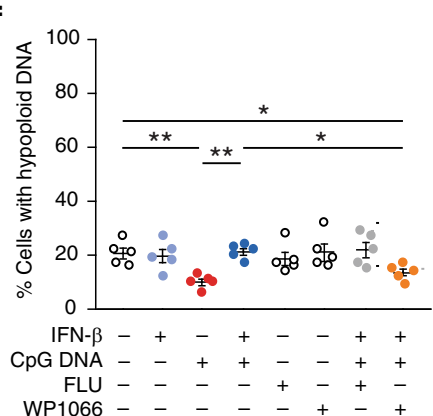

Fig. 5 IFN- $\beta$ promotes neutrophil apoptosis through STAT3 activation. a, b Human PMN $\left(5^{\star} 10^{6}\right.$ cells $\left./ \mathrm{ml}\right)$ were pretreated with human IFN- $\beta$ ( $\left.50-150 \mathrm{ng} / \mathrm{ml}\right)$ for $10 \mathrm{~min}$ and then challenged with CpG DNA for $30 \mathrm{~min}$. The cells were then lysed, cytosolic and nuclear fractions were prepared and immunoblotted for phospho-STAT1 (a) or phospho-STAT3 (b). $\beta$-actin served as a loading control. Blots are representative for 3 independent experiments. c-f Human PMN were pre-incubated with the STAT1 inhibitor fludarabine (FLU; $25 \mu \mathrm{M})$ or the STAT3 inhibitor WP1066 $(5 \mu \mathrm{M})$ for 30 min before addition of human recombinant IFN$\beta(50 \mathrm{ng} / \mathrm{ml})$ for $10 \mathrm{~min}$ and then challenged with CpG DNA. After culture for additional $24 \mathrm{~h}$, cell viability (c), annexin- $V$ staining (d), mitochondrial transmembrane potential ( $\triangle \Psi \mathrm{m}, \mathrm{CMXRos}$ staining) (e) and nuclear DNA content (f) were analyzed. Results are mean \pm SEM of 6 experiments with different blood donors. ${ }^{\star} P<0.05,{ }^{\star \star} P<0.01,{ }^{\star \star \star} P<0.001$ (Dunn's multiple contrast hypothesis test). Source data are provided as a Source Data file

PMN and macrophages containing apoptotic PMN at 24 and $48 \mathrm{~h}$ post-E. coli. Likewise, in the peritonitis model, treatment with exogenous IFN- $\beta$ enhanced efferocytosis assessed both in vivo and ex vivo and rescued hampered efferocytosis in $I f n b^{-/-}$ macrophages (Supplementary Fig. 7a, b). Moreover, exogenous IFN- $\beta$ facilitated macrophage reprogramming in LPS-stimulated WT mice and restored reprogramming in Ifn $b^{-/-}$macrophages, at least in part, as evidenced by increased IL-10 secretion with concomitant reduction in IL-12, IL-6, TNFa, and CCL3 secretion (Supplementary Fig. $7 \mathrm{c}-\mathrm{g}$ ). Thus, exogenous IFN- $\beta$ acts as a bona fide pro-resolving mediator in vivo by accelerating bacterial clearance, enhancing PMN apoptosis and efferocytosis, and macrophage reprogramming.

Irreversible loss of phagocytosis blunts efferocytic modules. Having shown that macrophages that lost their phagocytic capacity are key effectors in resolving inflammation and the contribution of IFN- $\beta$ to this process, we next characterized the properties of non-phagocytic macrophages, in particular with respect to the uptake of apoptotic cells. We found that the phagocytic capacity of $\mathrm{F} 4 / 80^{+}$macrophages (determined by the uptake of $\mathrm{PKH} 2-\mathrm{PCL}^{-}$green) was initially increased during the early phase of resolution of peritonitis $(24-48 \mathrm{~h})$ followed by significant reductions at $48-72 \mathrm{~h}$ PPI (Fig. 9a) without detectable changes in the percentage of phagocytic macrophages (Fig. 9b). Thus, the emergence of non-phagocytic macrophages was indeed due to a loss of phagocytic properties rather than to a loss of the phagocytic macrophage population.

Next, we examined whether various targets, like apoptotic cells or latex beads can promote loss of phagocytosis. To this end, we injected apoptotic cells, latex beads (LB) or IgG-opsonized LB labeled with green fluorescence alongside PKH2-PCL red into the peritoneal cavity during the resolving phase of peritonitis, and assessed the uptake of PKH2-PCL and labeled targets by macrophages. Our results show that only macrophages that engulfed high amounts of PKH2 were able to engulf LB or IgGopsonized LB (Fig. 9c-d), moreover these PKH2 $2^{\text {hi }}$ macrophages phagocytosed more apoptotic cells than their PKH2lo counterparts, while $\mathrm{PKH} 2^{-}$macrophages did not engulf apoptotic cells at all (Fig. 9e). Thus, PKH2 uptake correlates well with the phagocytosis of target particles, and the initial apoptotic cell engulfment seem to limit both efferocytosis and PKH2 acquisition. Along these lines, we also found that only apoptotic cells diminished PKH2 uptake by macrophages (36\% reduction), whereas LB or opsonized LB did not affect uptake (Fig. 9f-g). Since uptake of high numbers of apoptotic cells parallels with loss of phagocytosis, it is conceivable that its termination will lead to reversal of non-phagocytic macrophages to the phagocytic state. To address whether loss of phagocytosis is reversible, we first injected $\mathrm{PKH} 2$-green into mice undergoing peritonitis followed by an injection of $\mathrm{PKH} 2$-red $12 \mathrm{~h}$ later. Peritoneal macrophages were collected and analyzed for dye uptake at $4-8 \mathrm{~h}$ after the second injection (Fig. 9h), and $\mathrm{PKH} 2$-green ${ }^{+}$macrophages were phenotyped according to the dye ratio. Thus, macrophages that acquired equal amounts of $\mathrm{PKH} 2$-green and $\mathrm{PKH} 2$-red (the diagonal group in the dot-plot) represent sustained phagocytosis and constituted the majority of macrophages (Fig. 9i). Macrophages that engulfed more $\mathrm{PKH} 2$-red than $\mathrm{PKH} 2$-green represent increased phagocytosis and constituted a minute fraction of the population. Macrophages that engulfed more $\mathrm{PKH} 2$-green than $\mathrm{PKH} 2$-red represent reduced phagocytosis and the percentage of this subset increased with time while sustained phagocytosis was reduced (Fig. 9i, j show representative images and cumulative data, respectively). Our transcriptomic analysis revealed markedly 
a

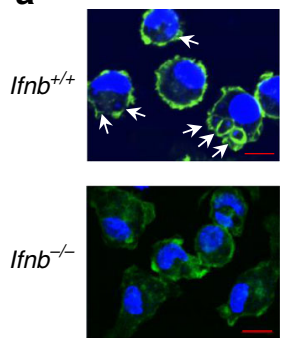

Green: phalloidin Blue: Hoechst b

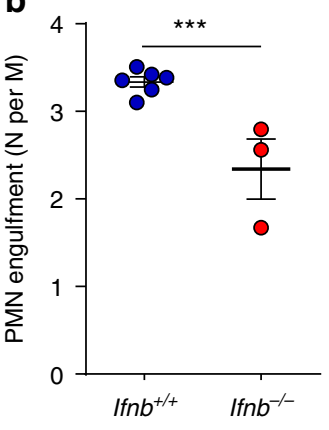

d Zymosan-initiated
peritonitis $(48 \mathrm{~h})$

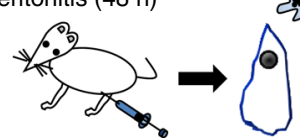

Peritoneal macrophages

CypHer-loaded apoptotic cells

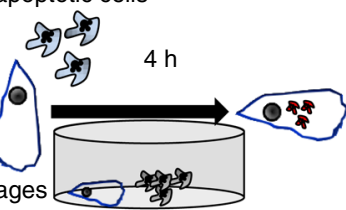

e
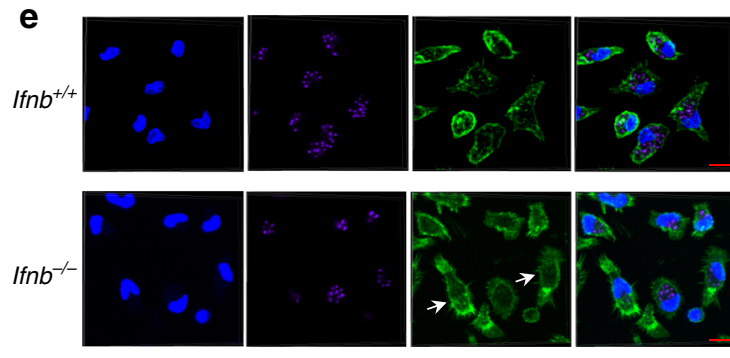

Hoechst

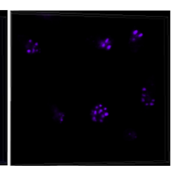

CypHer

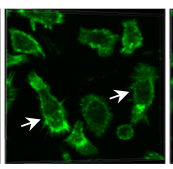

phalloidin

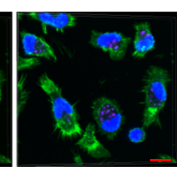

merged

h

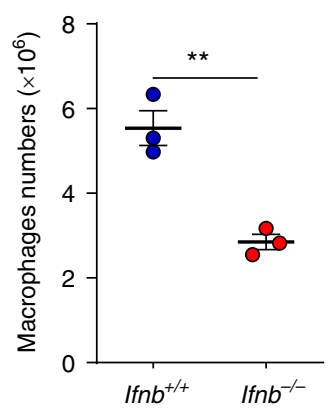

C
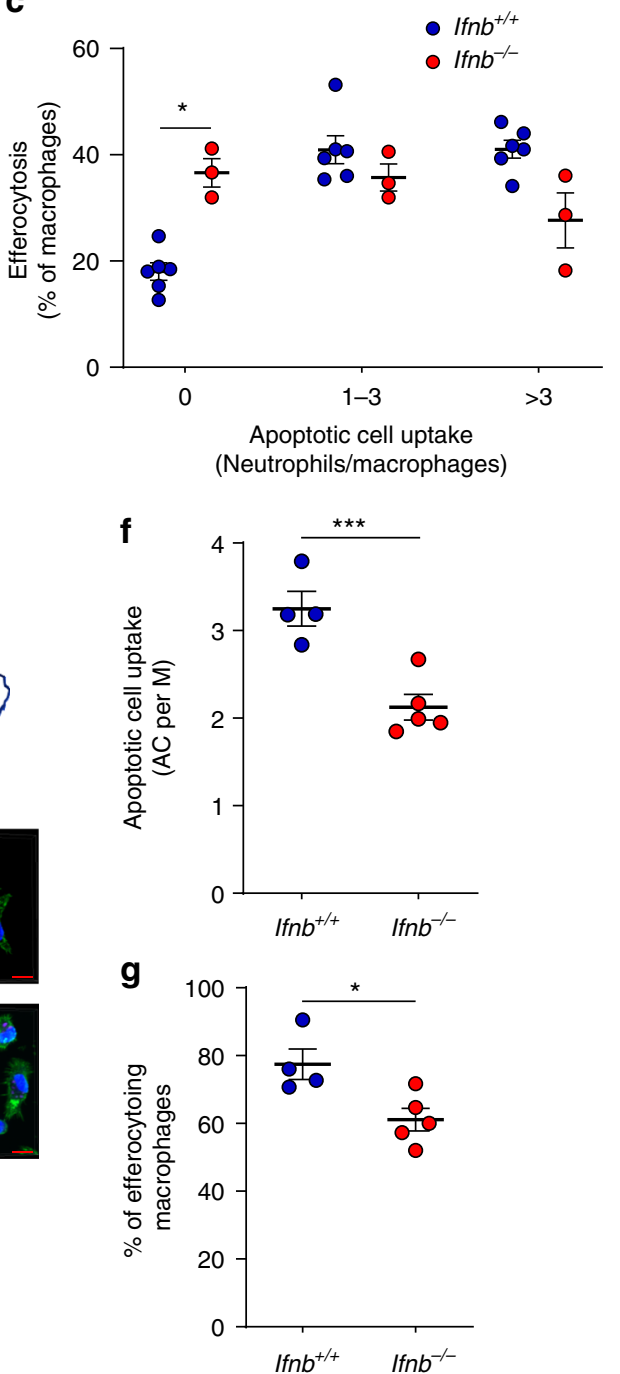

Fig. 6 IFN- $\beta$ enhances macrophage efferocytosis during the resolution of inflammation. a-c Peritoneal macrophages were recovered from male Ifnb ${ }^{+/ t}$ or Ifnb $\mathrm{f}^{-/-}$mice at $48 \mathrm{~h} \mathrm{PPI}$ and stained with Hoechst 33342 and FITC-phalloidin (a). Fluorescent images of select frames were taken using high-resolution microscopy achieved by 3D confocal (z-stack) scanning with a Nikon A1-R confocal fluorescent microscope. The number of apoptotic PMN nuclei in each macrophage were enumerated (see arrowheads for illustration) using the Nikon NIS-Elements microscope imaging software and average engulfment per macrophage (b) or engulfment according to thresholds (c) were calculated. Representative images (a) and means \pm SEM (b, c) for six (Ifnb $+/+$ ) and three (If $\mathrm{fb}^{-/-}$) experiments. d-f Peritoneal macrophages were recovered from male Ifn $b^{+/+}$or Ifn $b^{-/-}$mice at $48 \mathrm{~h} \mathrm{PPI}$ and incubated with CypHer-labeled apoptotic Jurkat cells at a ratio of 1:3. After $4 \mathrm{~h}$, unbound cells were washed and macrophages were stained with Hoechst 33342 and FITC-phalloidin (as illustrated in $\mathbf{d}$ ). Select images of each staining and merged images are shown (e). The number of engulfed apoptotic cells (AC) in each macrophage (M) were counted and average apoptotic cell uptake (f) and the percentage of efferocytosing macrophages (g) were calculated. $\mathbf{h}$ The total numbers of $\mathrm{F} 4 / 80^{+}$ peritoneal macrophages was detected by flow cytometry and calculated. Representative images $(\mathbf{e})$ and means \pm SEM $(\mathbf{f}-\mathbf{g})$ for four $\left(I f n b^{+/+}\right)$and five (Ifn $b^{-/-}$) independent experiments. ${ }^{\star} P<0.05,{ }^{\star \star \star} P<0.005$ (Student's $t$ test). Source data are provided as a Source Data file

reduced expression of the genes coding for the efferocytic receptors Mertk and CD206 with slight decreases in CD36 in non-phagocytic macrophages $(6.7,2.03$, and 1.46 fold reduction, respectively). Consistently, we detected significantly lower surface expression of all three efferocytic receptors (57\%, 64\%, and 49\% reduction for $\mathrm{CD} 36, \mathrm{CD} 206$, and Mertk, respectively) whereas
CD45 expression was unaffected (Fig. 9k-1). This expression profile resembles that of eosinophils that are non-phagocytic cells (Fig. 9l). Thus, macrophage loss of phagocytosis seems to be a progressive and irreversible process in vivo and is associated with reduced expression of efferocytic receptors through transcriptional and none-transcriptional mechanisms. 

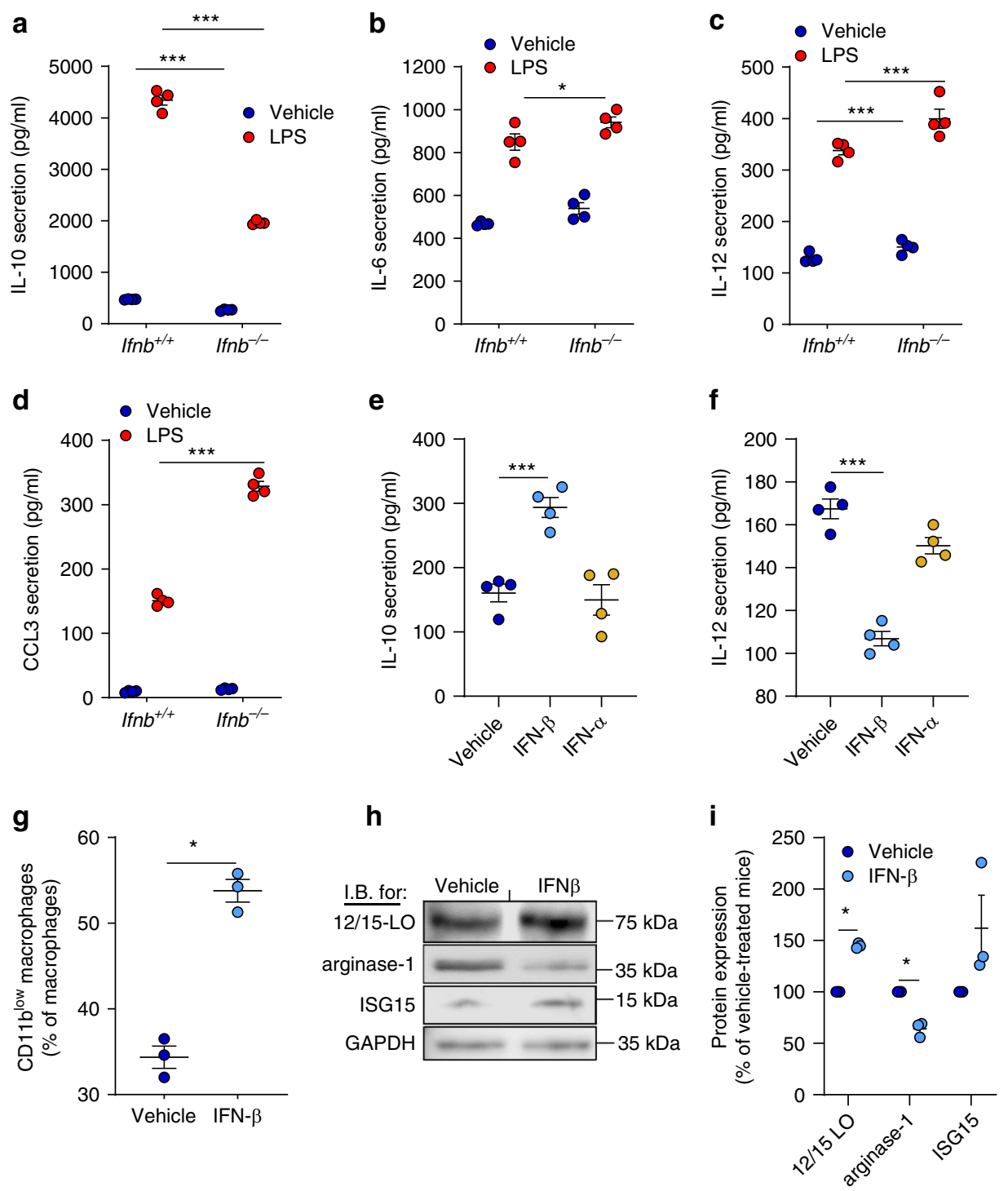

Fig. 7 IFN- $\beta$ favors macrophage reprogramming during the resolution of inflammation. a-d Macrophages were recovered from peritoneal exudates of male Ifn $\mathrm{b}^{+/+}$or Ifn $\mathrm{b}^{-/-}$mice at $48-66 \mathrm{~h} \mathrm{PPI}$ and cultured with LPS $(1 \mu \mathrm{g} / \mathrm{ml})$ for $24 \mathrm{~h}$. Culture supernatants were then collected and levels of IL-10 (a), IL-6 (b), IL-12 (c) and CCL3 (d) were determined by selective ELISAs. Results are means \pm SEM from four independent experiments. ${ }^{\star} P<0.05,{ }^{\star} * \star P<0.005$ (Tukey's HSD). e-f Macrophages were recovered from peritoneal exudates of Ifnb $b^{+/+}$mice at $48-66 \mathrm{~h}$ PPI and cultured with mouse IFN- $\beta$ or IFN- $\alpha$ $(20 \mathrm{ng} / \mathrm{ml}$ each) for $48 \mathrm{~h}$. Then, culture supernatants were collected and levels of IL-10 (e) and IL-12 (f) were determined by ELISA. Results are means \pm SEM $(n=4)$. ${ }^{\star \star \star} P<0.005$ (Tukey's HSD). $\mathbf{g}$ Macrophages were recovered from peritoneal exudates of Ifnb ${ }^{+/+}$mice $48-66 \mathrm{~h}$ PPI and incubated with IFN- $\beta$ $(20 \mathrm{ng} / \mathrm{ml})$ for $48 \mathrm{~h}$. The cells were then immunostained for F4/80 and CD11b and the percentage of CD11blow macrophages was determined by flow cytometry. Results are means \pm SEM from three independent experiments. ${ }^{\star \star \star} P<0.005$ (Tukey's HSD). h-i Mice undergoing peritonitis were treated with IFN- $\beta$ (20 ng/mouse, i.p.) or vehicle at $24 \mathrm{~h}$ PPI. Peritoneal macrophages were collected at $48 \mathrm{~h}$ PPI, lysed and immunoblotted for $12 / 15-\mathrm{LO}$, arginase 1 , ISG15 and GAPDH. Representative blots (h) and densitometry analysis (means \pm SEM) (i) for three independent experiments. ${ }^{\star} P<0.05$ (Student's $t$ test) Source data are provided as a Source Data file

\section{Discussion}

We demonstrate here a previously unappreciated role for IFN- $\beta$; upon its induction and secretion by non-phagocytic resolution phase macrophages, IFN- $\beta$ promotes neutrophil apoptosis and efferocytosis as well as polarization of macrophages towards a pro-resolving phenotype, thereby facilitating timely resolution of bacterial inflammation. We propose that IFN- $\beta$ mediates both feedback and bidirectional crosstalk between non-phagocytic macrophages, phagocytic macrophages and neutrophils, thereby defining a novel resolution circuit.

The role of specialized lipid mediators (SPM), like lipoxins, resolvins, protectins and maresins ${ }^{12}$ and proteins, such as annexin A1 and galectin- $1^{39-41}$ in limiting both inflammation and fibrotic tissue repair has been established in recent years. However, up to date, only 2 major cytokines have been associated with resolving inflammation, namely TGF- $\beta$ and IL-10. TGF- $\beta$ is produced during the resolution phase of spontaneously resolving inflammation in experimental animals ${ }^{10,42}$, and specifically following the uptake of apoptotic cells by macrophages ${ }^{43}$. IL-10 exerts paramount anti-inflammatory and anti-fibrotic activities ${ }^{44}$, albeit it is not always produced during the resolution phase of inflammation ${ }^{42}$. A common feature of both TGF- $\beta$ and IL-10 is the enhancement of clearance of apoptotic PMN via efferocytosis that is essential for prevention of chronic inflammation and autoimmunity $^{45}$ and limiting the production of proinflammatory cytokines ${ }^{43,46}$. Here we show that IFN- $\beta$ also 

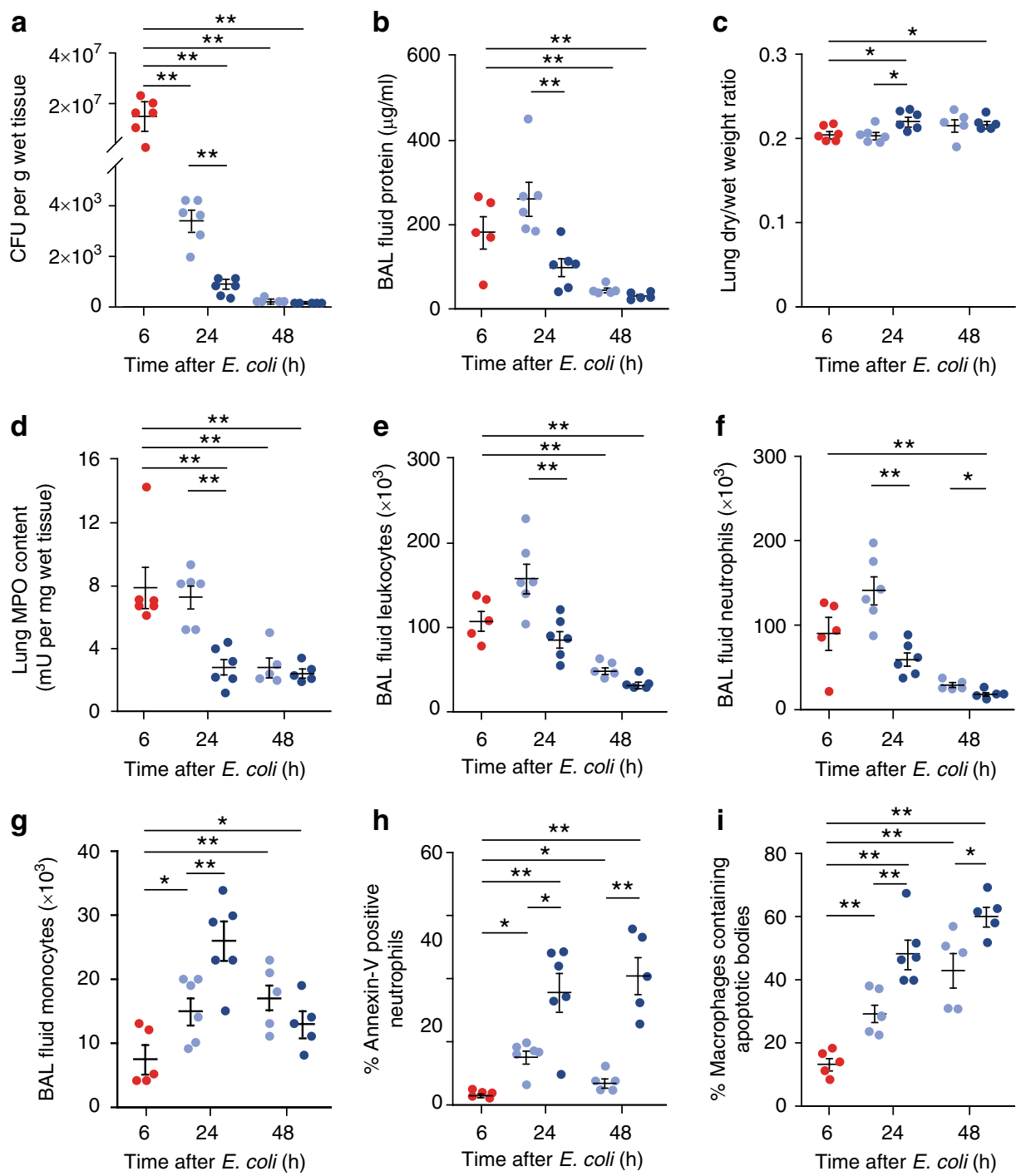

Fig. 8 IFN- $\beta$ treatment accelerates the resolution of $E$. coli pneumonia. Female C57BL/ 6 mice were injected intratracheally with $5^{\star} 10^{6}$ live $E$. coli. Six hours later (at the peak of inflammation), they were treated with mouse recombinant IFN- $\beta$ ( $50 \mathrm{ng} / 20 \mathrm{~g}$ b.w., intraperitoneally) or vehicle. At 24 or $48 \mathrm{~h}$ post- $E$. coli instillation, lungs were removed without lavage and analyzed for $E$. coli content (a), lung dry-to-wet weight ratio (c) and tissue MPO activity (d). In separate groups of mice bronchoalveolar lavage fluid protein concentration (b), total leukocyte (e), neutrophil (f) and monocyte/macrophage numbers (g), the percentage of annexin-V-positive (apoptotic) PMN (h), and the percentage of macrophages containing apoptotic bodies (i) were determined. Results are means \pm SEM ( $n=6$ mice per group for 6 and $24 \mathrm{~h}$ and 5 mice per group for $48 \mathrm{~h}$ ). ${ }^{\star} P<0.05,{ }^{\star \star} P<0.01$ (Dunn's multiple contrast hypothesis test). Source data are provided as a Source Data file

possesses similar properties. Previous studies have shown that intracellular annexin A1 facilitates TLR3 and TLR9-mediated IFN- $\beta$ production by macrophages ${ }^{47}$, and IFN- $\beta$ mediates the expression of the pro-resolving receptor FPR2 on macrophages ${ }^{48}$. Our RNA-Seq analysis (BioProject accession No: PRJNA450293) also indicate upregulated annexin A1 and FPR2 expression in non-phagocytic resolution phase macrophages (1.93 and 5.5. fold increase, respectively), presumably due to stimulation by engulfed apoptotic PMN and/or IFN- $\beta$. Hence, TLR-mediated sensing of apoptotic cell constituents might trigger an IFN- $\beta$-associated response in resolution phase macrophages.

Previous studies have shown that the uptake of apoptotic cells by phagocytes can initially enhance high-burden efferocytosis ${ }^{49}$, which will be limited when their oxidative stress and metabolic constraints dominate ${ }^{50}$. We have previously shown that a subset of $\mathrm{CD} 11 b^{\text {low }}$ macrophages that appear during the resolution phase of inflammation contain high numbers of apoptotic cells but are devoid of efferocytic activity and PKH2 acquisition ${ }^{9}$. Hence, these macrophages were termed satiated macrophages. Whether the uptake of apoptotic cells is the sole driving force of satiation is difficult to determine, though it is well-established that macrophage reprogramming to anti-inflammatory phenotypes ${ }^{2}$ and probably to the $\mathrm{CD} 11 \mathrm{~b}^{\text {low }}$ phenotype as well ${ }^{9}$ is mediated by efferocytosis in vivo. Hence, uptake of apoptotic cells, predominantly neutrophils, by macrophages during the resolution phase likely plays a paramount role in macrophage loss of phagocytosis and satiation. Our results demonstrate that the nonphagocytic phenotype in resolution phase macrophages exhibit increased transcription and secretion of IFN- $\beta$ but not other type I IFNs. Consistently, we detected higher IFN- $\beta$ levels in resolving exudates of the peritoneum and bronchoalveolar space parallel with increased rates of apoptotic death in infiltrating PMN. 
a

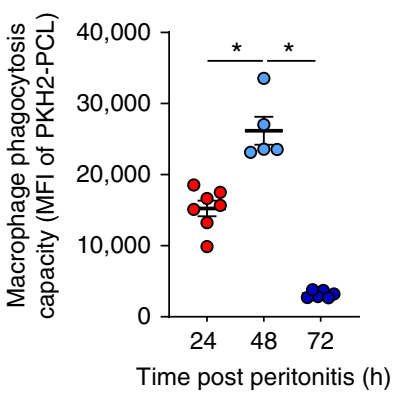

f

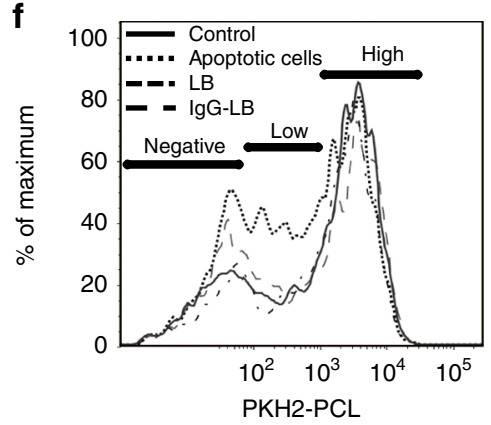

h

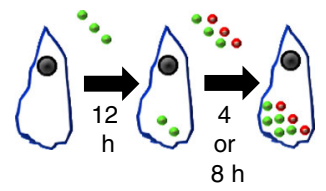

$4 \mathrm{~h}$

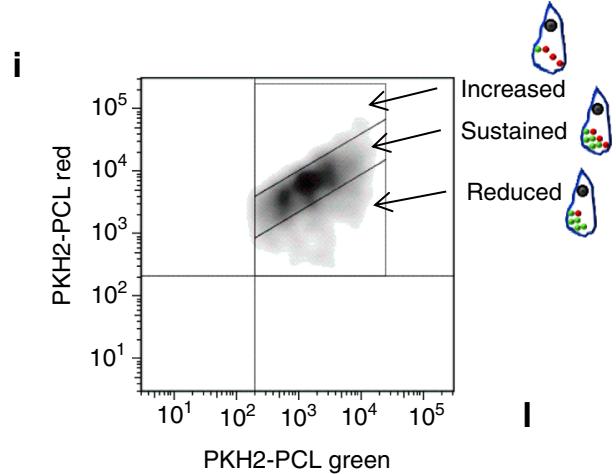

k

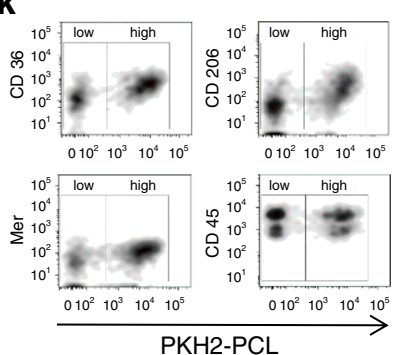

g

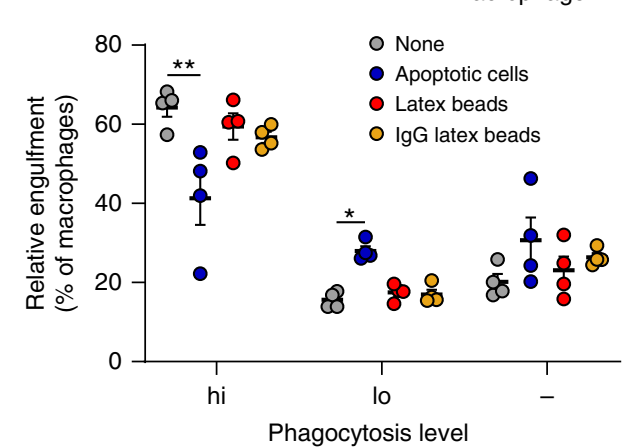

j

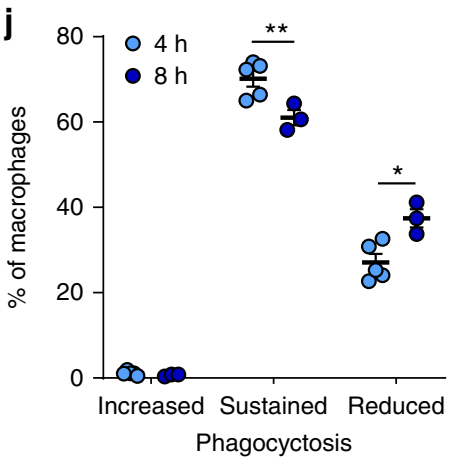

b
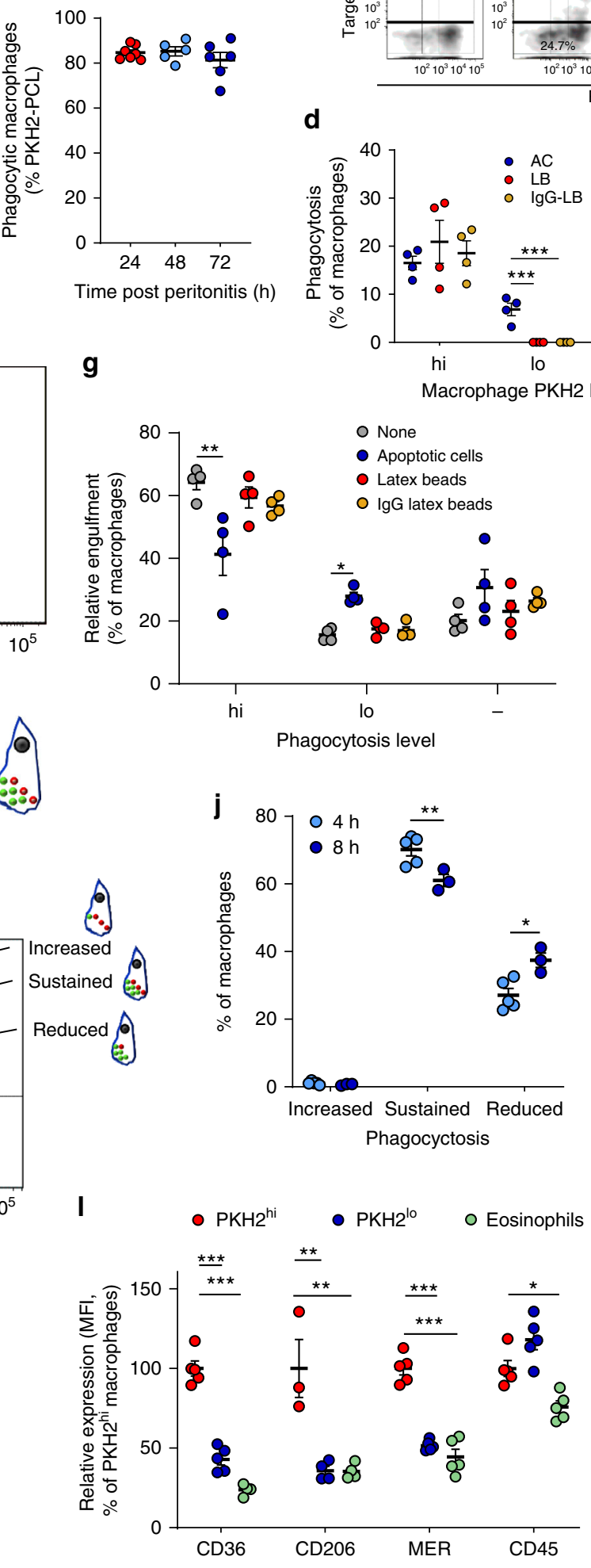

Apoptotic cells

IgG latex beads

Phagocyctosis

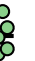

Importantly, genetic deletion or neutralization of IFN- $\beta$ lead to reduced PMN apoptosis in vivo as well as upon culture ex vivo. Conversely, treatment with exogenous IFN- $\beta$ enhanced neutrophil apoptosis both in the $E$. coli pneumonia and peritonitis models. It is important to note that IFN- $\beta$ effectively overrode survival cues from TLR ligands, such as CpG DNA and LPS, as well as the acute-phase protein serum amyloid $\mathrm{A}$, and redirected
C

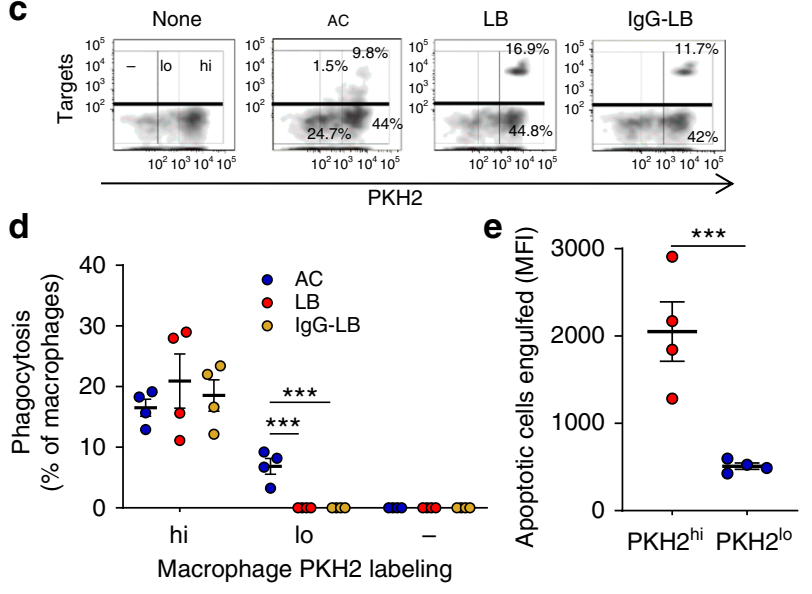

Latex beads

human PMN to apoptosis. Such an inhibitory action was still detectable when IFN- $\beta$ was added at $4 \mathrm{~h}$ post-challenge, further highlighting the therapeutic potential of this cytokine. Our results point toward STAT3 activation and increased Mcl-1 degradation as main mechanisms underlying the apoptosis-promoting action of IFN- $\beta$ in human PMN. Inflammatory activation of PMN seems essential for the pro-apoptotic activity of IFN- $\beta$. These findings 
Fig. 9 Characteristics of macrophages following loss of phagocytosis. $\mathbf{a}$, b The phagocyte-specific dye PKH2-PCL green was injected I.P. to male WT mice undergoing peritonitis for 20, 44 and $68 \mathrm{~h}$. After $4 \mathrm{~h}$, the peritoneal cells were recovered and immuno-stained for F4/80 and CD11b. PKH2-PCL green acquisition by CD11 high macrophages was determined by flow cytometry. Results are means \pm SEM ( $n=8$ mice for $24 \mathrm{~h}, 6$ mice for 48 h, and 7 mice for $72 \mathrm{~h}$ ) showing MFI (a) and the percentage of PKH2 ${ }^{+}$cells (b). ${ }^{\star} P<0.05$ (Tukey's HSD). c-g Mice were injected i.p. with $3 \times 10^{6}$ apoptotic Jurkat cells, latex beads, IgG-opsonized latex beads or vehicle together with PKH2-PCL red at $62 \mathrm{~h} \mathrm{PPI.} 4 \mathrm{~h}$ later, the peritoneal cells were recovered, immuno-stained for $\mathrm{F} 4 / 80$ and $\mathrm{CD} 11 \mathrm{~b}$ and F4/80+ macrophages were analyzed by flow cytometry for target particle uptake and/or PKH2 engulfment (designated as PKH2high, -low and -negative populations). Results are representative for three experiments presented as density or histogram plots (c, f) and means \pm SEM from 4 independent experiments of \% of phagocytic macrophages (d), particles engulfed (e), or PKH2 uptake ( $(\mathbf{g})$. ${ }^{\star} P<0.05,{ }^{\star \star} P<0.01$ (Tukey's HSD). $\mathbf{h}$, i PKH2-PCL green was injected I.P. to mice at $44 \mathrm{~h} \mathrm{PPI}$ followed by an injection of PKH2-PCL red at $58 \mathrm{~h}$ PPI. Peritoneal cells were recovered at 62 or $66 \mathrm{~h} \mathrm{PPI}$ and immuno-stained for F4/80 and CD11b and analyzed with flow cytometry (as illustrated in h). PKH2-PCL green vs. red acquisition was determined in $\mathrm{F} 4 / 80^{+}$macrophages and macrophages that displayed increased, sustained or reduced phagocytosis (representative dot-plot is shown in $\mathbf{i}$ ). j Data are means \pm SEM ( $n=5$ mice for $4 \mathrm{~h}$ and 3 mice for $8 \mathrm{~h}$ ). ${ }^{\star} P<0.05,{ }^{\star} * P<0.01$ (Student's $t$ test). $\mathbf{k}, \mathbf{I}$ PKH2-PCL red was injected I.P. to mice at $62 \mathrm{~h}$ PPI. $4 \mathrm{~h}$ later the peritoneal cells were recovered, immuno-stained for CD36, CD206 or MER, receptors involved in apoptotic cell uptake. Staining for CD45 served as a control. Receptor expression on PKH2-PCL-high ( $\mathrm{PKH} 2^{\text {hi }}$ ) or $\mathrm{PKH} 2-\mathrm{PCL}-$ low $\left(\mathrm{PKH} 2^{\mathrm{lo}}\right)$ macrophages was determined by flow cytometry. Results are representative from $n=4$ mice presented as dot plots (k) and means \pm SEM relative MFI normalized to PKH $2^{\text {hi }}$ macrophage expression (I). ${ }^{\star} P<0.05,{ }^{\star \star} P<0.01,{ }^{\star \star \star} P<0.005$ (Student's $t$ test). Source data are provided as a Source Data file

are in line with a previous report of IFN- $\beta$ promotion of apoptosis in tumor-infiltrating neutrophils ${ }^{25}$. Notably, increased IFN- $\beta$ levels were also detectable during the onset of inflammation in our peritonitis and pneumonia models. However, IFN- $\beta$ did not abrogate neutrophil recruitment to the inflamed peritoneum. Thus, the pro-resolving actions of IFN- $\beta$ on neutrophils can primarily be attributed to enhancing apoptosis and its consequences.

Our results demonstrate IFN- $\beta$ promotion of efferocytosis of apoptotic PMN in vivo during the resolution phase of peritonitis and pneumonia. Importantly, this pro-efferocytic activity was independent of enhancing PMN apoptosis since the uptake of apoptotic cells ex vivo was also abrogated in $I f n b^{-/-}$macrophages. The findings that both TGF- $\beta$ and apoptotic cells can induce IFN- $\beta$ secretion by resolution phase macrophages would raise the intriguing possibility that IFN- $\beta$ may, at least in part, mediate the pro-efferocytic activity of TGF- $\beta$, which is also produced during efferocytosis. We also show that IFN- $\beta$ is involved in the expression of IL-10 by resolution phase macrophages and the reprogramming of these macrophages to a pro-resolving phenotype. Since IL-10 also promotes engulfment of apoptotic cells ${ }^{51}$, it is conceivable that IL-10 might act downstream to or in concert with IFN- $\beta$ to promote efferocytosis.

During the resolution of inflammation macrophages that have engulfed high numbers of apoptotic PMN downregulate CD11b and $\mathrm{F} 4 / 80$ expression and become CD11b $\mathrm{b}^{\text {low }}$ macrophages $\mathrm{s}^{9,10}$. These macrophages might be converted from an M2-like profibrotic phenotype to a pro-resolving phenotype (termed Mres) that is characterized by the increased expression of the SPM producing enzyme 12/15-LO, and reduced expression of the M2 marker arginase $1^{52}$. Our transcriptome analysis confirms that phagocytic CD11b $b^{\text {high }}$ macrophages display an increased gene profile commensurate with an M2, reparative phenotype. Functional gene annotations relevant to this designation include blood vessel development, extracellular matrix, protein kinase activity, and cell morphogenesis involved in differentiation and cell adhesion. The phagocytic nature of these macrophages is highlighted by the increased expression of genes associated with endocytosis, membrane invagination, cytoskeletal protein binding and adhesion molecules. The loss of phagocytic properties that characterizes non-phagocytic resolution phase macrophages is associated with reduced expression of these functional gene groups and an increase in the expression of a distinct IFN- $\beta$ related gene signature with functional designations like immune, defense and inflammatory responses. Other upregulated gene groups that might be related to the non-phagocytic CD11b low phenotype include locomotor behavior and oxidation-reduction processes. These functions are linked to loss of phagocytic function and increased migration to remote sites, which are characteristic features of these macrophages ${ }^{9}$. Our results indicate that IFN- $\beta$ promoted macrophage efferocytosis and reprogramming, as well as polarization towards the Mres phenotype in vivo by increasing the percentage of $\mathrm{CD} 11 \mathrm{~b}^{\text {low }}$ macrophages in resolving exudates and the expression of $12 / 15-\mathrm{LO}$ while reducing the expression of arginase 1. Previous studies have reported additional actions of IFN- $\beta$ that are consistent with resolution. These include the induction of IL-10 following bacterial stimulation ${ }^{24,53}$, limiting the lethality of LPS $^{23}$, inhibition of lung fibrosis ${ }^{54}$ by reducing TGF- $\beta$ levels, and abrogating osteoclast development and inflammatory bone destruction ${ }^{55}$. Based on these and our current results, we conclude that IFN- $\beta$ is a paramount effector cytokine in resolving inflammation.

Since non-phagocytic macrophages are an important source of IFN- $\beta$ during the resolution of inflammation, we further characterized their properties and regulation of their tissue levels. Our results suggest that non-phagocytic macrophages are formed from the phagocytic pool of macrophages that originates from blood monocytes and characterized as $\mathrm{F} 4 / 80^{\mathrm{hi}}$ macrophages. As resolution progresses, the uptake of apoptotic PMN and other cells, but not other phagocytic targets, converts resolution phase macrophages to the non-phagocytic state with complete loss of phagocytic capacity. Subsequently, non-phagocytic macrophages will reduce surface expression of efferocytic receptors, like CD11b, CD36, CD206, and Mer as well as the transcripts of other efferocytosis-related genes, such as low-density lipoprotein receptor-related protein 1 (LRP1), ATP-binding cassette A1 (ABCA1), Dynamin 1 and 2, and dedicator of cytokinesis 1 (DOCK) 1 (BioProject accession No: PRJNA450293) ${ }^{56}$. IFN- $\beta$ expression in macrophages is associated with a posttranslational modification that generates $50-66 \mathrm{kDa}$ products that are stored in the secretory vesicles. These modifications need to be removed for secretion because macrophages release only the $25-35 \mathrm{kDa}$ form. Additional studies on the mechanism that controls the secretion of IFN- $\beta$ and possibly other cytokines as well, are undoubtedly warranted to further our understanding of the role of IFN- $\beta$. For clinical aspects of IFN- $\beta$ therapy please see Supplemental Discussion.

Collectively, our findings highlight the importance of efferocytic satiation and identify a novel IFN- $\beta$-mediated circuit that contributes to the termination of bacterial inflammation through facilitating PMN apoptosis and efferocytosis, and macrophage reprogramming to pro-resolving phenotypes. These findings would also suggest the therapeutic potential of IFN- $\beta$ in chronic 
and non-resolving inflammation, as well as fibrotic disorders and wound repair.

\begin{abstract}
Methods
Mice. Ifn $b^{-/-}$male and female mice (Erlandsson et al., 1998) were a kind gift from Prof. Issazadeh-Navikas (University of Copenhagen). C57BL/6 WT male and female mice were purchased from Harlan Laboratories and Charles River Laboratories, respectively. All mice were aged 8-15 weeks and did not undergo previous procedures. All mice were fully backcrossed to C57BL/6 and housed under a $12 \mathrm{~h}: 12 \mathrm{~h}$ light-dark cycle and specific pathogen-free conditions, up to 5 mice per cage. Mice were fed standard pellet chow and reverse osmosis water ad libitum. Animal experiments were approved by the Committee of Ethics, University of Haifa (authorization no. 246/14) or the Animal Care Committee, Maisonneuve-Rosemont Hospital (protocol no. 2015/31) and mice were maintained under the respective committee's ethical regulations for animal testing and research.
\end{abstract}

Human blood donors. Venous blood $(20 \mathrm{ml}$, anticoagulated with sodium heparin, $50 \mathrm{U} / \mathrm{ml}$ ) was obtained from nonsmoking apparently healthy volunteers (male and female, 26-65 years) who had denied taking any medication for at least 2 weeks. The Clinical Research Committee at the Maisonneuve-Rosemont Hospital approved the experimental protocols (project no. 99097) and each volunteer provided written informed consent.

\begin{abstract}
Mouse peritonitis model. Male C57BL/6 Ifnb $b^{-/-}$or Ifn $b^{+/+}$mice were randomly assigned to experimental groups. Mice were injected I.P. with zymosan A $(1 \mathrm{mg} / \mathrm{ml}$ in PBS, $1 \mathrm{ml}$ per mouse). PKH2-PCL green $(0.25 \mathrm{mM}, 0.5 \mathrm{~mL})$ was injected I.P. at $62 \mathrm{~h}$ and peritoneal exudates were collected $4 \mathrm{~h}$ later. Peritoneal cells were stained with PE-conjugated rat anti-mouse F4/80 (1:100, Biolegend 123110), and PerCPconjugated rat anti-mouse $\mathrm{CD} 11 \mathrm{~b}(1: 100$, Biolegend 101230$)$ and $\mathrm{F} 4 / 80^{+}$macrophages were sorted using the FACSaria III sorter (Beckton-Dickinson). In separate experiments, peritoneal exudates were collected from unchallenged mice or 4, 24, $48,66-72$ or $96 \mathrm{~h}$ post-zymosan A and cellular content was analyzed by flow cytometry as above. In separate experiments, mice challenged with zymosan A for $42 \mathrm{~h}$ or unchallenged were injected intraperitoneally with pre-made liposomal clodronate ( 1 or $0.1 \mathrm{mg} /$ mouse, respectively) or empty liposomes. Then, unchallenged mice were injected with zymosan A. After additional $24 \mathrm{~h}$, peritoneal fluids were collected from all mice and analyzed by Western blotting for IFN- $\beta$ as indicated below. Clodronate treatment resulted in an $84 \%$ reduction in peritoneal macrophages and no significant changes in the percentage of splenic macrophages.
\end{abstract}

Mouse pneumonia model. Under isoflurane anesthesia, female C57BL/6 mice were first injected I.P. with saline, rat anti-mouse IFN- $\beta$ monoclonal $\mathrm{Ab}$ (clone 7FD3, Abcam) or isotype-matched rat IgG1 (Abcam) (both at $1 \mu \mathrm{g} / 20 \mathrm{~g}$ b.w. in $200 \mu \mathrm{l}$ sterile saline) followed by intratracheal instillation of $5^{*} 10^{6}$ CFU live E. coli (American Type Culture Collection, ATCC 25922) in $50 \mu \mathrm{l}$ saline. In separate groups of mice, first pneumonia was induced by intratracheal instillation of live $E$. coli, followed $6 \mathrm{~h}$ later (at the peak of inflammation) by intraperitoneal injection of carrier-free recombinant mouse IFN- $\beta 1$ (Biolegend) $(50 \mathrm{ng} / 20 \mathrm{~g}$ b.w. in $200 \mu \mathrm{l}$ sterile saline) or vehicle. At 6,24 or $48 \mathrm{~h}$ post- $E$. coli, the lungs were lavaged (4 times with $1 \mathrm{ml}$ heparinized saline) or processed without lavage. Aliquots of homogenized lung were cultured to evaluate $E$. coli colony numbers. Bronchoalveolar lavage (BAL) fluid protein, and total and differential leukocyte counts were determined using standard techniques. Apoptosis in neutrophils (identified as Ly6G-positive cells) was assessed using flow cytometry with FITC-conjugated annexin- $\mathrm{V}$ (BD Biosciences). The percentage of macrophages containing apoptotic bodies was assessed following cell staining with hematoxylin and eosin. Lungs removed without lavage were used to determine dry-to-wet weight ratio and tissue myeloperoxidase activity, an index of PMN infiltration. Myeloperoxidase activity was measured using o-dianisidine as a substrate and human MPO (Sigma) as a standard.

\begin{abstract}
Human neutrophil culture. Neutrophils were isolated from peripheral blood by centrifugation through a Ficoll-Hypaque gradient, sedimentation through dextran ( $3 \% \mathrm{wt} / \mathrm{vol})$, and hypotonic lysis of erythrocytes. Neutrophils $\left(5 \times 10^{6} \mathrm{cells} / \mathrm{ml}\right.$, purity $>95 \%$, viability $>98 \%$, apoptotic $<2 \%$ ) were cultured in RPMI 1640 medium supplemented with $10 \%$ autologous serum with human recombinant IFN$\beta$ (25-150 ng/ml, PeproTech) and then challenged with CpG DNA $(1.6 \mu \mathrm{g} / \mathrm{ml}, E$. coli strain B, Sigma), LPS (10 $\mu \mathrm{g} / \mathrm{ml}$, E. coli O111:B4, Sigma), serum amyloid A $(10 \mu \mathrm{g} / \mathrm{ml}$, PeproTech $)$ with or without fludarabine $(25 \mu \mathrm{M})$ or WP1066 $(5 \mu \mathrm{M})$. In some experiments, neutrophils were first challenged with CpG DNA and treated with IFN- $\beta$ at $1-4 \mathrm{~h}$ later. To study phagocytosis-induced apoptosis, neutrophils were cultured with live E. coli (American Type Culture Collection, ATCC 25922) at a ratio of $1: 7$ with or without IFN- $\beta$ ( $50 \mathrm{ng} / \mathrm{ml})$. At the designated time points, cells were processed as described below.
\end{abstract}

RNA-Seq. Total RNA from sorted cells was extracted using Aurum Total RNA kit (Bio-Rad Laboratories, Inc.). RNA integrity score was determined by Agilent 2100
Bioanalyzer using the Agilent RNA 6000 Pico kit (Agilent Technologies). Samples were prepared for Illumina sequencing using NEB's Ultra Directional RNA Library Prep Kit for Illumina (NEB\#7420). Libraries were sequenced with a $50 \mathrm{bp}$ SR run on Illumina HiSeq 2500 using a V3 flow cell. Sequenced reads were compared to available murine Ensembl 70 genes using mouse genome build (GRCm38), and expression was compared between macrophage subtypes using two separate analysis pipelines: RSEM/EdgeR and topaht2/cuffdiff. Depending on the pipeline, between $\sim 1500-2500$ genes were found to be differentially expressed (FDR $<0.05$ ), with a wide overlap in results between the two pipelines. Significance values presented were from the topaht $2 /$ cuffdiff analysis. Gene ontology enrichment analysis was performed with the DAVID Bioinformatics Resources 6.7 software.

Flow cytometry. Macrophages were recovered from peritoneal exudates of $\mathrm{Ifn} \mathrm{b}^{+/+}$ mice 48-66 h PPI and immunostained immediately or incubated $\left(1 \times 10^{6}\right.$ cells in $1 \mathrm{~mL}$ of culture media) with IFN- $\beta(20 \mathrm{ng} / \mathrm{ml})$ for $48 \mathrm{~h}$. Then, the cells were immunostained with PE anti-mouse F4/80 and PerCP anti-mouse/human CD11b Abs $(0.2 \mu \mathrm{g}$ per million cells each in $100 \mu \mathrm{l}$, BioLegend). For detection of intracellular IFN- $\beta$ protein, peritoneal cells were fixed ( $1 \%$ PFA/PBS $\left./ 15^{\prime} / \mathrm{RT}\right)$, permeabilized $(0.05 \%$ Tween-20 in $2.5 \% \mathrm{BSA}, 30 \mathrm{~min}$ on ice) and immunostained with rat anti-IFN $\beta$ (lug per million cells in $100 \mu \mathrm{l}$, Abcam ab24324) and anti-rat Alx488 as a secondary antibody $(0.5 \mu \mathrm{g}$ per million cells in $100 \mu \mathrm{l}$, Invitrogen A21208). Cell populations were evaluated by flow cytometry using FACSCanto II (BD) and analyzed by the FlowJo software (Treestar). In some experiments, the phagocytespecific dye PKH26-PCL red was injected I.P. to mice undergoing peritonitis for $62 \mathrm{~h}$ and $4 \mathrm{~h}$ later the peritoneal cells were recovered and immunostained as above and with Alexa Fluor 647 anti-mouse CD206 (MMR) (141712), PerCP anti-mouse CD45 (103130) or Alexa Fluor 647 anti-mouse CD36 (102610) Abs (0.2 $\mu \mathrm{g}$ per million cells each in $100 \mu \mathrm{l}$, BioLegend) or APC anti-mouse MERTK (10 $\mu \mathrm{l}$ per million cells, R\&D Systems FAB5912A). In some experiments, peritoneal cells from unchallenged or zymosan A challenged $(48 \mathrm{~h})$, Ifn $b^{+/+}$or Ifn $b^{-1-}$ mice were immune-stained with PE-conjugated rat anti-mouse F4/80 and APCconjugated anti-mouse Tim4 (1:50, Miltenyi Biotec 130-116-758), and analyzed by flow cytometry. Flow cytometry gating strategies are depicted in Supplementary Fig. $8^{57}$.

Surface expression of IFN $\alpha / \beta R 1$ on human freshly isolated PMN or on neutrophils challenged with CpG DNA $(1.6 \mu \mathrm{g} / \mathrm{ml})$ for 1 or $2 \mathrm{~h}$ was assessed using R-phycoerythrin-conjugated mouse anti-human IFNaR1 monoclonal Ab (R\&D Systems) and an isotype-matched irrelevant Ab with a FACSCalibur flow cytometer and CellQuestPro software (BD Biosciences). Uptake of FITC-labeled ODN 2395 (Invitrogen) by human neutrophils challenged with IFN- $\beta(12.5-50 \mathrm{ng} / \mathrm{ml})$ or CpG DNA $(1.6 \mu \mathrm{g} / \mathrm{ml})$ for $30 \mathrm{~min}$ was assessed by flow cytometry.

Generation of apoptotic cells. Jurkat T cells (from Prof. Yablonski, The Technion, Israel) were incubated $\left(1 \times 10^{6}\right.$ cells $/ \mathrm{ml}$ of culture media) for $4 \mathrm{~h}$ with $1 \mu \mathrm{M}$ staurosporine (Sigma). In some experiments, cells were then washed with serumfree media and incubated $\left(10 \times 10^{6}\right.$ cells $\left./ \mathrm{ml}\right)$ for 30 min with $10 \mathrm{mM}$ CypHer5E Mono NHS Ester (GE Healthcare). Then, cells were washed twice with culture medium before incubation with macrophages.

IFN- $\boldsymbol{\beta}$ detection. Peritoneal exudates and bronchoalveolar lavage fluid were collected at the indicated times and the levels of IFN- $\beta$ in cell-free fluids were determined by VeriKine-HS Mouse Interferon Beta Serum ELISA Kit (Pestka Biomedical Laboratories, Inc). In some experiments, macrophages were recovered $66 \mathrm{~h}$ post PPI, separated using PE-conjugated anti-F4/80 Abs (1ul per $10^{\star} 10^{6}$ cells in 100ul, Biolegend 123110) with PE selection magnetic beads (StemCell Technologies) and incubated $\left(1 \times 10^{6}\right.$ cells in $1 \mathrm{ml}$ of culture media) with TGF- $\beta$ $(5 \mathrm{ng} / \mathrm{ml})$, poly (I:C) $(4 \mu \mathrm{g} / \mathrm{ml})$ or apoptotic cells ( $1: 5$ ratio) for $24 \mathrm{~h}$. Then, IFN- $\beta$ content in conditioned culture media was determined by ELISA.

Apoptosis assays. Peritoneal PMN were recovered from Ifn $b^{+/+}$or $I f n b^{-/-}$mice at $24 \mathrm{~h}$ PPI, separated using PE-conjugated Grl antibodies with PE selection magnetic beads (StemCell Technologies) and incubated $\left(1^{\star} 10^{6}\right.$ cells in $1 \mathrm{ml}$ of culture media) with or without IFN- $\beta$ ( $20 \mathrm{ng} / \mathrm{ml})$ and/or Q-VAD $(10 \mu \mathrm{M})$ for $24 \mathrm{~h}$. Bronchoalveolar lavage fluid cells were resuspended in $100 \mu \mathrm{PBS} .2^{*} 10^{5}$ cells were stained with Annexin-V-FITC and PI MEBCYTO Apoptosis Kit (MBL Laboratories). Apoptosis was evaluated by flow cytometry using FACSCanto II (BD Biosciences) and analyzed by FlowJo software (Treestar). Alternatively, PMN lysates were prepared after $6 \mathrm{~h}$ of culture and immunoblotted for active (cleaved) caspase-3 using specific antibodies (Cell Signaling Technology).

Apoptosis in human PMN was assessed by flow cytometry with FITCconjugated annexin-V (BD Biosciences) in combination with propidium iodide (Molecular Probes). For nuclear DNA analysis, neutrophils were suspended in $0.2 \mathrm{ml} 0.1 \%$ sodium citrate solution containing $50 \mathrm{ug} / \mathrm{ml}$ propidium iodide and $0.1 \%$ Triton X-100 immediately before assay. Mitochondrial transmembrane potential was monitored following neutrophil staining with the lipophilic fluorochrome chloromethyl-X-rosamine (CMXRos, $20 \mathrm{nM}$, Millipore-Sigma) and the fluorescence was analyzed in a FACSCalibur flow cytometer. 
Ex vivo stimulation for cytokine secretion. Peritoneal macrophages were recovered from Ifn $b^{+/+}$or Ifn $b^{-I-}$ mice $48-66 \mathrm{~h}$ PPI, separated as above and incubated $\left(1^{\star} 10^{6}\right.$ cells in $1 \mathrm{~mL}$ of culture media) overnight with LPS $(1 \mu \mathrm{g} / \mathrm{ml})$. Next, culture supernatants were collected and IL-10, IL-6, IL-12 and CCL3 levels were determined by standard ELISA (Biolegend). In some experiments, macrophages were recovered from peritoneal exudates of Ifn $b^{+/+}$mice $48-66 \mathrm{~h}$ PPI and incubated with IFN- $\beta$ or IFN- $\alpha(20 \mathrm{ng} / \mathrm{ml}$ each) for $48 \mathrm{~h}$. Then, culture supernatants were collected and IL-10 and IL-12 levels were determined by standard ELISA. In some experiments, Ifn $b^{+/+}$or Ifn $b^{-/-}$mice were injected with vehicle or recombinant mouse IFN- $\beta 1$ ( $25 \mathrm{ng} /$ mouse) $24 \mathrm{~h}$ prior to exudate recovery and peritoneal macrophages were recovered at $48-66 \mathrm{~h}$ PPI.

Phagocytosis assays in vivo. The phagocyte-specific dyes PKH2-PCL green or PKH26-PCL red were injected I.P. to mice undergoing peritonitis for 20, 44 and $68 \mathrm{~h}$. In some experiments, apoptotic Jurkat cells, latex beads, IgG-opsonised latex beads $\left(3^{*} 10^{6}\right.$ particles each) or vehicle were injected together with PKH2-PCL green $62 \mathrm{~h}$ after peritonitis initiation. After $4 \mathrm{~h}$, the peritoneal cells were recovered and immuno-stained for F4/80 and CD11b. Alternatively, PKH2-PCL green was injected I.P. to mice undergoing peritonitis for $44 \mathrm{~h}$ and at $58 \mathrm{~h}$ PKH26-PCL red was injected. At 62 or $66 \mathrm{~h}$ post peritonitis initiation, the peritoneal cells were recovered and immuno-stained as just described.

Immunofluorescence microscopy and image analysis. For in vivo engulfment evaluation, peritoneal macrophages were recovered from Ifn $b^{+/+}$or Ifn $b^{-/-}$mice $48 \mathrm{~h} \mathrm{PPI}$, separated as above and fixed with $4 \%$ paraformaldehyde $+5 \%$ sucrose to 8 well chamber glass slides. Fixed cells were stained overnight at $4{ }^{\circ} \mathrm{C}$ with CF 488 phalloidin (1:40; biotium 00042 or 1:1,000; Chem Cruz) followed by Hoechst (1:500; Molecular Probes) and the slides were mounted with SlowFade ${ }^{\mathrm{mt}}$ Gold Antifade Mountant (Molecular Probes). The slides were imaged using a Nikon A1$\mathrm{R}$ confocal laser scanning microscope and engulfment was calculated using Nikon NIS-Elements microscope imaging software. For ex vivo engulfment evaluation, macrophages were recovered from Ifn $b^{+/+}$or Ifn $b^{-I-}$ mice $48 \mathrm{~h}$ PPI, separated and incubated $\left(10^{\star} 10^{6}\right.$ Jurkat cells in $1 \mathrm{ml}$ of culture media) with $10 \mu \mathrm{M}$ CypHer5E Mono NHS Ester-labeled apoptotic Jurkat cells (1:3 ratio, GE Healthcare) and vehicle or IFN- $\beta(25 \mathrm{ng} / \mathrm{ml})$. After $4 \mathrm{~h}$, unbound cells were washed and the cells were stained as above. In some experiments, Ifn $b^{+/+}$or Ifn $b^{-1-}$ mice were injected with vehicle or recombinant mouse IFN- $\beta 1$ ( $25 \mathrm{ng} /$ mouse) $24 \mathrm{~h}$ prior to exudate recovery and peritoneal macrophages were recovered at $48-66 \mathrm{~h}$ PPI and analyzed as above.

Organelle fractionation. RAW264.7 macrophages were incubated with apoptotic Jurkat cells (1 to 3 ratio) for $24 \mathrm{~h}$, washed with PBS and resuspended in $1 \mathrm{ml}$ of ice cold HB buffer supplemented with protease inhibitor cocktail (Roche). The cells were mechanically disrupted in a glass homogenizer and nuclear and cell debris were removed by centrifugation at $110 \times g$ for $5 \mathrm{~min}$ at $4^{\circ} \mathrm{C}$. Obtained PNS was carefully applied on top of $4 \mathrm{ml}$ of 10 to $35 \%$ OptiPrep (Sigma) gradient and centrifuged for $2 \mathrm{~h}$ using SW55 Ti swing Rotor (Beckman Coulter, USA) at 100,000 $\times g$ at $4^{\circ} \mathrm{C}$. After centrifugation, $1 \mathrm{ml}$ from the top of the tube was removed and $300 \mu$ fractions were collected thereafter. The collected fractions were mixed with sample buffer, boiled and equal volumes of samples were analyzed using Western blotting.

Western blot analysis. Protein extracts of sorted populations ( $<98 \%$ purity) of $\mathrm{PKH} 2-\mathrm{PCL}^{\text {hi }}$ and $\mathrm{PKH} 2-\mathrm{PCL}^{\text {lo }}$ macrophages were resolved by SDS-PAGE, transferred to PVDF membranes (Bio-Rad Laboratories, Inc.), blocked with 5\% skimmed milk powder and immunoblotted with either rabbit anti-human IFN- $\beta$ Ab (1ug/ml, Abcam ab24324), rabbit anti-mouse ISG-15 (1:200, Santa-Cruz Biotechnology sc-50367) or goat anti-human GAPDH (1:200, Santa-Cruz Biotechnology sc-20357). Lysates from $10^{7}$ human neutrophils were probed with antibodies to Mcl-1 (1:1,000, Proteintech, cat. No. 16225-1-AP), or YY1 (1:1,000, Santa Cruz Biotechnology, clone H-10, cat. No. sc-7341). For STAT analysis, nuclear and cytosolic fractions from $10^{7}$ human neutrophils were prepared with a NE-PER Nuclear and Cytosolic Extraction kit (Pierce) and probed with antibodies to phospho-STAT-1 (1:1,000, Cell Signaling, clone 58D6, cat. No. 9167), phosphoSTAT3 (1:1,000, Cell Signaling, clone D3A7, cat. No. 9145), YY1 (Santa Cruz Biotechnology) or $\beta$-actin (1:1,000, Millipore-Sigma, clone AC-15, cat No. A1978). Alternatively, macrophage lysates, from mice treated with IFN- $\beta$ ( $20 \mathrm{ng} /$ mouse, i.p.) $24 \mathrm{~h}$ PPI, were immunoblotted for 12/15-LO (1:1,500, Cayman 160704), arginase 1 (1:20,000, Abcam ab60176), ISG15 and GAPDH. Then, the membranes were washed and incubated with the appropriate HRP-conjugated secondary antibodies and developed using WesternBright ${ }^{\text {tw }}$ ECL (Advansta Inc) or Clarity Max ${ }^{\mathrm{TM}}$ ECL (BioRad). Band density was quantified with National Institutes of Health (NIH) ImageJ software (http://rsb.info.nih.gov/ij/) and was expressed as a ratio of unstimulated cells after correction for loading discrepancies. All unprocessed blots are provided in the Source Data File.

Statistics. Statistical significance of differences between indicated samples was determined by unpaired Student's $t$ test or one-way ANOVA followed by Dunn's multiple contrast hypothesis test or Tukey's HSD, using the SPSS software versions 21/24 (IBM) as indicated. Correlations were assessed by the Spearman rank correlation coefficient. $P$ values were indicated as ${ }^{*} p<0.05,{ }^{* *} p<0.01$ and ${ }^{* * *} p<$ 0.005 .

Reporting Summary. Further information on research design is available in the Nature Research Reporting Summary linked to this article.

\section{Data availability}

RNA sequence data have been deposited in BioProject under the primary accession code PRJNA450293. All other data are available in the article (and its Supplementary Information files), The source data underlying Figs. 1d-h, 2a-k, 3a-i, 4a-m, 5a-f, 6b, c, 6f-h, 7a-i, 8a-i, 9a, b, 9d, e, 9g, 9j, 91 and Supplementary Figs. 1b-f, 2a-g, 3a, b, 4a-c, $5 \mathrm{a}-\mathrm{r}, 6 \mathrm{~b}, \mathrm{c}, 7 \mathrm{a}-\mathrm{g}$ are provided as a Source Data file.

Received: 30 June 2018 Accepted: 5 June 2019

Published online: 02 August 2019

\section{References}

1. Rossi, A. G. et al. Cyclin-dependent kinase inhibitors enhance the resolution of inflammation by promoting inflammatory cell apoptosis. Nat. Med. 12, 1056-1064 (2006)

2. Ortega-Gomez, A., Perretti, M. \& Soehnlein, O. Resolution of inflammation: an integrated view. EMBO Mol. Med. 5, 661-674 (2013).

3. Headland, S. E. \& Norling, L. V. The resolution of inflammation: Principles and challenges. Semin. Immunol. 27, 149-160 (2015).

4. Uderhardt, S. et al. 12/15-lipoxygenase orchestrates the clearance of apoptotic cells and maintains immunologic tolerance. Immunity 36, 834-846 (2012).

5. Elliott, M. R. \& Ravichandran, K. S. The dynamics of apoptotic cell clearance. Dev. Cell 38, 147-160 (2016).

6. Millet, A. et al. Proteinase 3 on apoptotic cells disrupts immune silencing in autoimmune vasculitis. J. Clin. Invest. 125, 4107-4121 (2015).

7. Bosurgi, L. et al. Macrophage function in tissue repair and remodeling requires IL-4 or IL-13 with apoptotic cells. Science 356, 1072-1076 (2017)

8. Das, A. et al. Correction of MFG-E8 resolves inflammation and promotes cutaneous wound healing in diabetes. J. Immunol. 196, 5089-5100 (2016).

9. Schif-Zuck, S. et al. Saturated-efferocytosis generates pro-resolving CD11b (low) macrophages: Modulation by resolvins and glucocorticoids. Eur. J. Immunol. 41, 366-379 (2011).

10. Sugimoto, M. A. et al. Plasmin and plasminogen induce macrophage reprogramming and regulate key steps of inflammation resolution via annexin A1. Blood 129, 2896-2907 (2017).

11. Han, S. et al. A Novel Subset of Anti-Inflammatory CD138 $(+)$ Macrophages Is Deficient in Mice with Experimental Lupus. J. Immunol. 199, 1261-1274 (2017).

12. Serhan, C. N. Pro-resolving lipid mediators are leads for resolution physiology. Nature 510, 92-101 (2014).

13. Derouet, M., Thomas, L., Cross, A., Moots, R. J. \& Edwards, S. W. Granulocyte macrophage colony-stimulating factor signaling and proteasome inhibition delay neutrophil apoptosis by increasing the stability of Mcl-1. J. Biol. Chem. 279, 26915-26921 (2004)

14. Jozsef, L., Khreiss, T. \& Filep, J. G. CpG motifs in bacterial DNA delay apoptosis of neutrophil granulocytes. FASEB J. 18, 1776-1778 (2004).

15. Francois, S. et al. Inhibition of neutrophil apoptosis by TLR agonists in whole blood: involvement of the phosphoinositide 3-kinase/Akt and NF-kappaB signaling pathways, leading to increased levels of Mcl-1, A1, and phosphorylated Bad. J. Immunol. 174, 3633-3642 (2005).

16. Vago, J. P. et al. Annexin A1 modulates natural and glucocorticoid-induced resolution of inflammation by enhancing neutrophil apoptosis. J. Leukoc. Biol. 92, 249-258 (2012).

17. Solito, E. et al. A novel calcium-dependent proapoptotic effect of annexin 1 on human neutrophils. FASEB J. 17, 1544-1546 (2003).

18. El Kebir, D. et al. 15-epi-lipoxin A4 inhibits myeloperoxidase signaling and enhances resolution of acute lung injury. Am. J. Respir. Crit. Care Med. 180, 311-319 (2009).

19. El Kebir, D., Gjorstrup, P. \& Filep, J. G. Resolvin E1 promotes phagocytosisinduced neutrophil apoptosis and accelerates resolution of pulmonary inflammation. Proc. Natl Acad. Sci. USA 109, 14983-14988 (2012).

20. Guarda, G. et al. Type I interferon inhibits interleukin-1 production and inflammasome activation. Immunity 34, 213-223 (2011).

21. Kelly-Scumpia, K. M. et al. Type I interferon signaling in hematopoietic cells is required for survival in mouse polymicrobial sepsis by regulating CXCL10. J. Exp. Med. 207, 319-326 (2010).

22. Karaghiosoff, M. et al. Central role for type I interferons and Tyk2 in lipopolysaccharide-induced endotoxin shock. Nat. Immunol. 4, 471-477 (2003).

23. Yoo, C. H. et al. Interferon beta protects against lethal endotoxic and septic shock through SIRT1 upregulation. Sci. Rep. 4, 4220 (2014). 
24. Perkins, D. J. et al. Reprogramming of murine macrophages through TLR2 confers viral resistance via TRAF3-mediated, enhanced interferon production. PLoS Pathog. 9, e1003479 (2013).

25. Andzinski, L. et al. Delayed apoptosis of tumor associated neutrophils in the absence of endogenous IFN-beta. Int J. Cancer 136, 572-583 (2015).

26. Jablonska, J., Wu, C. F., Andzinski, L., Leschner, S. \& Weiss, S. CXCR2mediated tumor-associated neutrophil recruitment is regulated by IFN-beta. Int. J. Cancer 134, 1346-1358 (2014).

27. Lee, P. Y. et al. Type I interferon modulates monocyte recruitment and maturation in chronic inflammation. Am. J. Pathol. 175, 2023-2033 (2009).

28. Yoshida, H., Okabe, Y., Kawane, K., Fukuyama, H. \& Nagata, S. Lethal anemia caused by interferon-beta produced in mouse embryos carrying undigested DNA. Nat. Immunol. 6, 49-56 (2005).

29. Lavin, Y. et al. Tissue-resident macrophage enhancer landscapes are shaped by the local microenvironment. Cell 159, 1312-1326 (2014).

30. Bang, S. et al. GPR37 regulates macrophage phagocytosis and resolution of inflammatory pain. J. Clin. Invest. 128, 3568-3582 (2018).

31. Nishi, C., Toda, S., Segawa, K. \& Nagata, S. Tim4- and MerTK-mediated engulfment of apoptotic cells by mouse resident peritoneal macrophages. Mol. Cell Biol. 34, 1512-1520 (2014).

32. Ahn, J., Ruiz, P. \& Barber, G. N. Intrinsic self-DNA triggers inflammatory disease dependent on STING. J. Immunol. 193, 4634-4642 (2014).

33. Michels, J., Johnson, P. W. \& Packham, G. Mcl-1. Int J. Biochem. Cell Biol. 37, 267-271 (2005).

34. Moulding, D. A., Quayle, J. A., Hart, C. A. \& Edwards, S. W. Mcl-1 expression in human neutrophils: regulation by cytokines and correlation with cell survival. Blood 92, 2495-2502 (1998).

35. Aswad, M., Assi, S., Schif-Zuck, S. \& Ariel, A. CCL5 promotes resolutionphase macrophage reprogramming in concert with the atypical chemokine receptor d6 and apoptotic polymorphonuclear cells. J. Immunol. 199, 1393-1404 (2017).

36. Fadok, V. A. et al. Macrophages that have ingested apoptotic cells in vitro inhibit proinflammatory cytokine production through autocrine/paracrine mechanisms involving TGF-beta, PGE2, and PAF. J. Clin. Invest. 101, 890-898 (1998).

37. Pashover-Schallinger, E. et al. The atypical chemokine receptor D6 controls macrophage efferocytosis and cytokine secretion during the resolution of inflammation. FASEB J. 26, 3891-3900 (2012).

38. Chiang, N. et al. Infection regulates pro-resolving mediators that lower antibiotic requirements. Nature 484, 524-528 (2012).

39. Perretti, M., Leroy, X., Bland, E. J. \& Montero-Melendez, T. Resolution pharmacology: opportunities for therapeutic innovation in inflammation. Trends Pharm. Sci. 36, 737-755 (2015).

40. Perucci, L. O. et al. Annexin A1 and specialized proresolving lipid mediators: promoting resolution as a therapeutic strategy in human inflammatory diseases. Expert Opin. Ther. Targets 21, 879-896 (2017).

41. Sundblad, V., Morosi, L. G., Geffner, J. R. \& Rabinovich, G. A. Galectin-1: a jack-of-all-trades in the resolution of acute and chronic inflammation. $J$. Immunol. 199, 3721-3730 (2017).

42. Bannenberg, G. L. et al. Molecular circuits of resolution: formation and actions of resolvins and protectins. J. Immunol. 174, 4345-4355 (2005).

43. Henson, P. M. \& Bratton, D. L. Antiinflammatory effects of apoptotic cells. J. Clin. Invest 123, 2773-2774 (2013).

44. Wynn, T. A. \& Vannella, K. M. Macrophages in Tissue Repair, Regeneration, and Fibrosis. Immunity 44, 450-462 (2016).

45. Korns, D., Frasch, S. C., Fernandez-Boyanapalli, R., Henson, P. M. \& Bratton, D. L. Modulation of macrophage efferocytosis in inflammation. Front Immunol. 2, 57 (2011).

46. Voll, R. E. et al. Immunosuppressive effects of apoptotic cells. Nature 390, 350-351 (1997).

47. Bist, P. et al. Annexin-A1 regulates TLR-mediated IFN-beta production through an interaction with TANK-binding kinase 1. J. Immunol. 191, 4375-4382 (2013).

48. Ampomah, P. B., Moraes, L. A., Lukman, H. M. \& Lim, L. H. K. Formyl peptide receptor 2 is regulated by RNA mimics and viruses through an IFNbeta-STAT3-dependent pathway. FASEB J. 32, 1468-1478 (2018).

49. Wang, Y. et al. Mitochondrial fission promotes the continued clearance of apoptotic cells by macrophages. Cell 171, 331-345 e322 (2017).
50. Park, D. et al. Continued clearance of apoptotic cells critically depends on the phagocyte Ucp2 protein. Nature 477, 220-224 (2011).

51. Campana, L. et al. The STAT3-IL-10-IL-6 pathway is a novel regulator of macrophage efferocytosis and phenotypic conversion in sterile liver injury. $J$ Immunol 200, 1169-1187 (2017).

52. Ariel, A. \& Serhan, C. N. New Lives given by cell death: macrophage differentiation following their encounter with apoptotic leukocytes during the resolution of inflammation. Front. Immunol. 3, 4 (2012).

53. Eshleman, E. M. \& Lenz, L. L. Type I interferons in bacterial infections: taming of myeloid cells and possible implications for autoimmunity. Front. Immunol. 5, 431 (2014).

54. Azuma, A. et al. Interferon-\{beta\} inhibits bleomycin-induced lung fibrosis by decreasing transforming growth factor-\{beta $\}$ and thrombospondin. Am. J. Respir. Cell Mol. Biol. 32, 93-98 (2005).

55. Takayanagi, H. et al. RANKL maintains bone homeostasis through c-Fosdependent induction of interferon-beta. Nature 416, 744-749 (2002).

56. Poon, I. K., Lucas, C. D., Rossi, A. G. \& Ravichandran, K. S. Apoptotic cell clearance: basic biology and therapeutic potential. Nat. Rev. Immunol. 14, 166-180 (2014)

57. Maceiras, A. R. et al. T follicular helper and $\mathrm{T}$ follicular regulatory cells have different TCR specificity. Nat. Commun. 8, 15067 (2017).

\section{Acknowledgements}

If $n b^{-/-}$mice were kindly provided by Prof. Shohreh Issazadeh-Navikas, University of Copenhagen, Denmark. This study was supported by grants from the Israel Science Foundation (Grant No. 678/13), the Rosetrees Trust and the Wolfson Family Charitable Trust (to A.A.) and the Canadian Institutes of Health Research (MOP-97742 and MOP 102619) (to J.G.F.). S.K.S. is the recipient of the PBC postdoctoral fellowship from the Israeli Council of Higher Education (MALAG), and S.S. is a recipient of a presidential scholarship from the University of Haifa.

\section{Author contributions}

S.K.S, D.E.K, S.S, S.B, M.S, J.S, N.P, S.A, A.O. and S.S-Z performed experiments and analyzed the results. D.E.K and S.S-Z assisted in planning the experiments and writing the manuscript. S.K.S. Y.F, N.S and A.A. performed the genetic and bioinformatics analyses, and deposited the data online. D.B, assisted in image acquisition and analysis J.G.F and A.A planned the experiments, analyzed the data and wrote the manuscript.

\section{Additional information}

Supplementary Information accompanies this paper at https://doi.org/10.1038/s41467019-10903-9.

Competing interests: The authors declare no competing interests.

Reprints and permission information is available online at http://npg.nature.com/ reprintsandpermissions/

Peer review information: Nature Communications thanks the anonymous reviewer(s) for their contribution to the peer review of this work. Peer reviewer reports are available.

Publisher's note: Springer Nature remains neutral with regard to jurisdictional claims in published maps and institutional affiliations.

Open Access This article is licensed under a Creative Commons Attribution 4.0 International License, which permits use, sharing, adaptation, distribution and reproduction in any medium or format, as long as you give appropriate credit to the original author(s) and the source, provide a link to the Creative Commons license, and indicate if changes were made. The images or other third party material in this article are included in the article's Creative Commons license, unless indicated otherwise in a credit line to the material. If material is not included in the article's Creative Commons license and your intended use is not permitted by statutory regulation or exceeds the permitted use, you will need to obtain permission directly from the copyright holder. To view a copy of this license, visit http://creativecommons.org/ licenses/by/4.0\%

(C) The Author(s) 2019 